\title{
Utilising inorganic nanocarriers for gene delivery
}

Xian Jun Loh ${ }^{\mathrm{a}, \mathrm{b}, \mathrm{c}, *}$, Tung-Chun Lee ${ }^{\mathrm{d}, *}$, Qing Qing Dou ${ }^{\mathrm{a}}, \mathrm{G}$. Roshan Deen ${ }^{\mathrm{e}}$

${ }^{a}$ Institute of Materials Research and Engineering, $A * S T A R,($ Agency for Science, Technology and Research), 3 Research Link, Singapore 117602, Singapore

E-mail:lohxj@imre.a-star.edu.sg,

Tel: $+65-65131612$

${ }^{b}$ Department of Materials Science and Engineering, National University of Singapore, Singapore 117574, Singapore

${ }^{c}$ Singapore Eye Research Institute, 20 College Road, Singapore 169856, Singapore

${ }^{d}$ UCL Institute for Materials Discovery and Department of Chemistry, University College London, Christopher Ingold Building, 20 Gordon Street, London WC1H OAJ, United Kingdom

${ }^{e}$ Soft Materials Laboratory, Natural Sciences and Science Education, National Institute of Education, Nanyang Technological University, 1-Nanyang Walk, 637616 Singapore

\begin{abstract}
The delivery of genetic materials into cells to elicit cellular response has been greatly studied by biomaterials scientists globally. Many materials such as lipids, peptides, viruses, synthetically modified cationic polymers and certain inorganic nanomaterials could be used to complex the negatively charged plasmids and deliver the formed package into cells. The recent literature on the delivery of genetic material utilising inorganic nanoparticles is carefully examined in this review. We pick out the most relevant references and concisely summarise the findings with illustrated examples. We further propose alternative approaches and suggest future pathways towards the practical use of multifunctional nanocarriers.
\end{abstract}




\section{INTRODUCTION}

\section{Gene delivery}

Recent advances in gene therapy have paved the way towards the effective treatment of human diseases originating from defective genes, such as cancers, Parkinson's disease, cystic fibrosis and muscular degeneration. ${ }^{1-4}$ Effective and specific in vivo delivery of therapeutic genetic materials into a cell, however, remains as a major challenge and is generally considered as the crucial factor in determining the potency of a particular gene therapy. ${ }^{5-8}$ In spite of their high efficiency and common usage in gene delivery, viral vectors inherit fundamental drawbacks (immunological problems, insertional mutagenesis and limitations in the size of the carried therapeutic genes) that need to be addressed before any human clinical trials can be safely conducted. ${ }^{7}$ Polymeric, lipid and peptide carriers have been extensively studied in recent years. ${ }^{9-17}$ Functional inorganic nanomaterials recently emerged as robust and versatile nanoscaffolds for effective gene delivery applications. ${ }^{5,6}$ Significantly, without the limitations associated with viral vectors, inorganic nanomaterials further offer an appealing set of properties for practical applications, including scalability in synthesis, facile functionalization, chemical and thermal stability. These properties are important for sterilization, low inherent toxicity (especially for gold, iron oxide and silica nanoparticles), availability in a wide range of size and shape, and the possibility of real-time tracking by various spectroscopic techniques.

\section{Concept}

In general, an effective nanocarrier needs to provide robust protection of nucleic acid from degradation by nucleases, efficient cell entry through the cell membrane, and release of the nucleic acid in its functional form within the nucleus (Scheme 1). ${ }^{18}$ This was typically achieved by tailoring the size and the surface functionalities (charges, hydrophobicity, and 
targeting groups) of the nanomaterials employed in gene delivery. Owing to the phosphate backbone, DNA and small interfering RNA (siRNA) are negatively charged moieties. Hence, nanoscaffolds with positively charged surface groups can noncovalently conjugate to DNA or RNA via electrostatic attractions, as have been widely employed in various nanoscaffold delivery systems. Another approach involves covalent tethering of genetic materials onto the nanoscaffolds, where subsequent release of genetic materials is triggered by a specific stimulus either internally or externally (Scheme 1). Plasmid DNA and siRNA are the two main categories of genetic material to be delivered to cells for gene therapy. siRNA is able to cause RNA interference (RNAi) and post-transcriptional gene silencing. This has sparked research interest in utilising RNAi for both biomedical research and therapeutic applications. Due to high negative charges, 'naked' plasmid DNA and siRNA cannot cross cellular membranes freely. Meanwhile, siRNA is easily digested by enzymes and DNase existing in the environment. Therefore, siRNA must be delivered under protection before reaching its destination and then be activated after delivery. The carriers must meet several requirements to be effective, including the ability to condense genetic materials into compact complexes that can be readily taken up by cells, efficient protection of genetic material from degradation by nucleases, and release of the genetic material in functional form. 


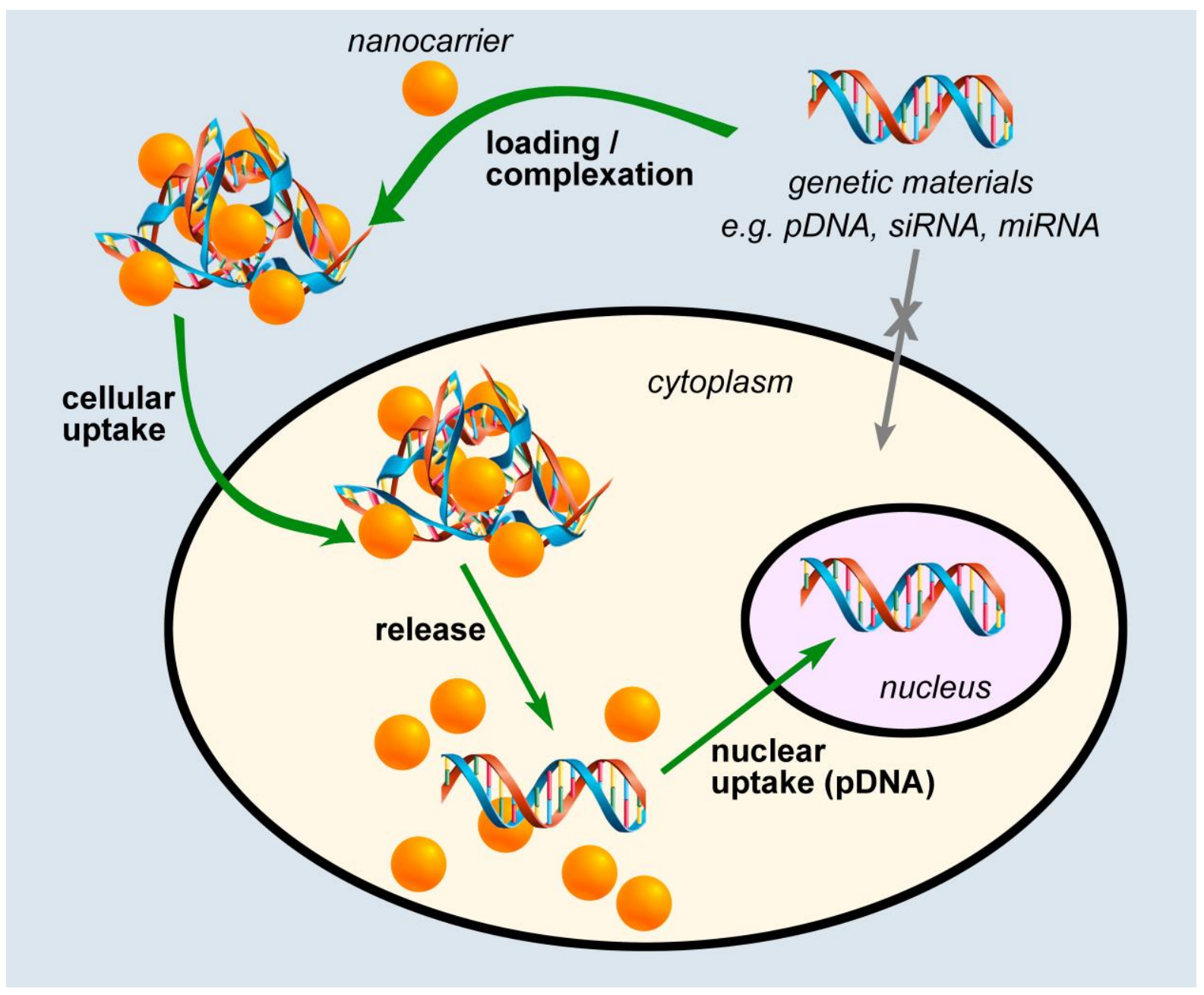

Scheme 1. Fundamental steps of gene delivery by nanocarriers (orange spheres).

\section{Delivery and tracking}

Specific delivery and efficient release of genetic materials from their carriers are prerequisites for an effective therapy. Specific delivery / targeting could be achieved "actively" or "passively". 19, 20 "Active" targeting involves delivery of genetic materials aided either internally by the molecular-recognition-driven binding between a functional nanocarrier and the receptors on the membrane of a target cell, or externally by a magnetic gradient as in the case of magnetic nanoparticles. On the other hand, "passive" targeting relies on kinetically driven pre-concentration of genetic materials in unhealthy tissues by extravasation through the leaky blood vessels with $600 \mathrm{~nm}$ gaps. This type of enhanced permeation and retention 
effect (EPR) favors loaded nanoscaffolds with a tailored size of around 5-10 nm to "passively" target on the unhealthy tissues. ${ }^{21}$ Nevertheless, non-specific uptake and potential degradation by macrophages can be problematic for systems relying only on the "passive" targeting method. Pun et al. recently reported the effects of various physicochemical parameters (size, PEGylation, and ligand type) on regulating non-specific versus targetspecific uptake. ${ }^{22}$ Release of genetic payload from the nanocarriers could similarly be triggered by internal (e.g. glutathione $(\mathrm{GSH})$, or $\mathrm{pH}$ ) or external (e.g. light) stimuli. ${ }^{23-25}$ Notably, biochemical control can be achieved utilising the internal stimuli, whereas spatiotemporal control can be done utilising external stimuli.

There exist other factors that determine the effectiveness of gene therapy, including the coexistence of numerous gene mutations in many diseases and the short lifetime of therapeutic DNA within the dividing cells. On top of that, real-time non-invasive visualization of the delivery event was shown to be an important criterion in assessing the mechanism of a given gene therapy. ${ }^{8}$ Hence, there are an increasing number of delivery systems incorporated with various probes for monitoring the delivery process. Nanoscaffold delivery systems are advantageous in this aspect owing to their unique optical and/or magnetic properties allowing non-invasive and spatio-temporal molecular imaging of gene delivery.

\section{NANOPARTICLES FOR GENE DELIVERY}

In recent publications, inorganic nanoparticles such as, gold nanoparticles, iron oxide nanoparticles, and quantum dots, have been reported as alternative gene delivery vehicles. This was suggested on account of their unique intracellular behaviors with powerful cellular imaging capacities. The following sections will discuss various types of inorganic 
nanoparticles and nanoscaffolds that have been suggested and the current stage of their research thus far.

\section{Gold nanoparticles (AuNPs)}

AuNPs have been popularly studied as multifunctional gene carriers due to their ease of synthesis, excellent biocompatibility, well-defined surface chemistry, and facile molecular imaging utilising fluorescence resonance energy transfer (FRET). A typical methodology for the preparation of AuNP-based gene delivery vectors is via surface functionalization of the nanoparticles with positively charged molecules such as amino acids, cationic peptides, and tertiary amine-containing molecules (Figure 1). ${ }^{26,27}$ This creates a positively charged scaffold allowing the binding of DNA or siRNA for the formation of complexes which can then be taken up by the cells. Other methods include the exploitation of gold-thiol chemistry to conjugate genetic materials directly onto AuNPs as well as the layer-by-layer assembly of PEI and siRNA to form the gene nanocarriers. However, a major drawback of these methods is that the synthetic process requires multi-step surface functionalization and subsequent conjugation with cationic moieties. This produces a heterogeneous mixture of polyelectrolyte complexes which limits the effectiveness of these gene carriers. Recently, a new method to circumvent this effect was developed to prepare highly efficient and non-toxic AuNP gene carriers with controlled size and surface charge. ${ }^{28}$ In that work, controlled synthesis of polyethyleneimine (PEI)-coated AuNPs was achieved utilising catechol-conjugated PEI (PEIC) for siRNA delivery. The reductive catechol groups drive the formation of spherical multicored micelles in aqueous solution and act as reductive templates for the growth of spherical AuNPs. Utilising these templates, AuNPs with tunable sizes and surface charges could be obtained. The PEI-coated AuNPs demonstrated low toxicity and an excellent gene silencing effect in cancer cells. Cebrian et al. have studied the effect of particle size on cell 
transfection. ${ }^{29}$ AuNPs, combined with PEI were used to prepare two sets of PEI-coated Au NPs having particle-size distributions centered at about $6 \mathrm{~nm}(<10 \mathrm{~nm}$ Au-PEI NPs $)$ or $70 \mathrm{~nm}$ (<100 nm Au-PEI NPs), respectively. Au-PEI NPs were coupled to a variety of plasmids carrying reporter or suicide genes to prepare Au-PEI NPs/DNA complexes. Human osteosarcoma Saos-2 cells were used to investigate the performance of the Au-PEI NPs as transfection vectors in serum-containing media. Cells were efficiently transfected with complexes derived from $<10 \mathrm{~nm}$ Au-PEI NPs, but not with the <100 nm Au-PEI NPs. Large aggregates of NPs associated with DNA were found in endocytic vesicles of cells incubated with <100 nm Au-PEI NPs, while the success of the smaller Au-PEI NPs as transfection vectors was related to their lower agglomeration state inside cells and to endosomal escape of DNA.

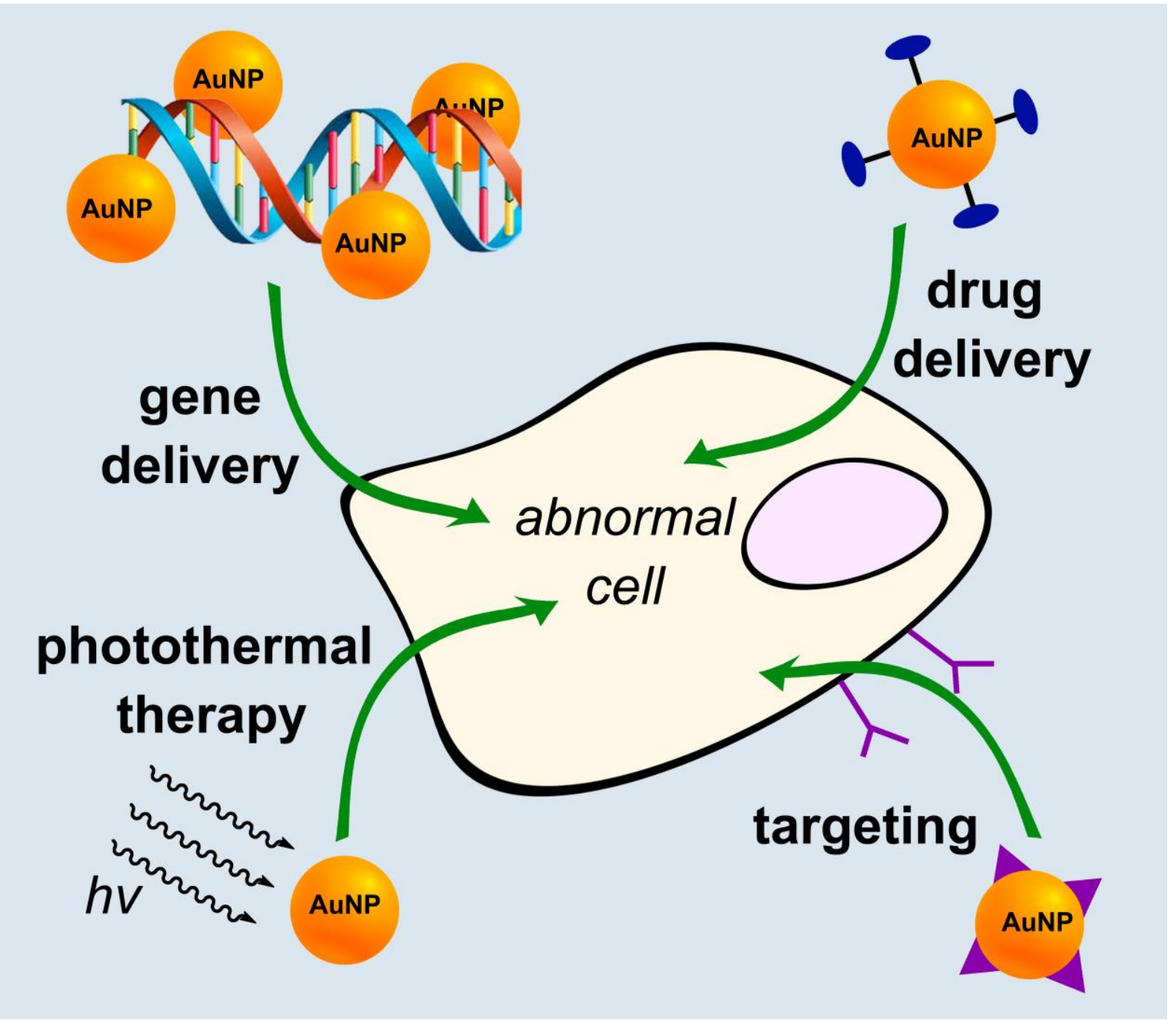


Figure 1. Gold nanoparticles (orange spheres) as multifunctional nanocarriers.

The development of gold nanoparticles for gene delivery have greatly facilitated the development of mixed monolayer protected gold nanoparticles, complexes of polymer and gold nanoparticles, double-stranded DNA functionalized gold nanoparticles, and single stranded DNA functionalized gold nanoparticles. ${ }^{30-34}$ Single-stranded DNA functionalized gold nanoparticles developed by Mirkin et al. demonstrated excellent gene delivery efficiency. ${ }^{31}$ These nanoparticles demonstrated greater knockdown of gene expression, higher binding affinity for target DNA, higher immunity to nuclease, and lower cell toxicity than antisense DNA delivered by either Lipofectamine or Cytofectin. In another attempt to develop an effective gene delivery system for a material (e.g., oligo antisense DNAs specific to a target gene) which allows the inhibition of the expression of a target gene without affecting normal cell physiology, a gene delivery system was fabricated in which an universal binding partner is covalently linked to the surface of a nanomaterial followed by binding an inhibitory molecule having the sequence of the target gene of interest to be expressed as a binding counter-partner, contributing to inhibition or expression of the target gene in a more effective manner. ${ }^{35}$ In 2005, Japanese inventors created cationic gold nanoparticle or the polyethylene glycol (PEG)-modified cationic gold nanoparticles bearing a cationic cysteamine surface for gene delivery. The gold nanoparticle-nucleic acid complexes or the PEG-modified cationic gold nanoparticle-nucleic acid complexes, capable of delivering the nucleic acids to the interior of a cell or an in vivo tissue were produced by bonding the resultant gold nanoparticles to the nucleic acids. Interestingly, these complexes were internalized into the cells by the use of optical tweezers. ${ }^{36}$ In another approach, DNA loaded gold nanoparticles embedded in sharp carbonaceous carriers were used for efficient DNA delivery into plants. The "nanogold" embedded carbon matrices were prepared by heat 
treatment of biogenic intracellular gold nanoparticles. The advantages of the composite carrier are the low plasmid and gold requirements. Plant cell damage utilising these gene delivery agents was minimal compared to that of the commercial micrometer sized gold particles. The efficient gene delivery can be attributed to the sharp edges that the carbon supports possess, which lead to better piercing capabilities with minimum damage. ${ }^{37}$ Gasphase self-assembly was used to synthesize biocompatible Au@PDMS-PLL soft nanocomposites which can be used for gene delivery and also photothermal therapy. ${ }^{38}$ Shan et al. reported a new gene delivery vector based on dendrimer-entrapped gold nanoparticles (Au DENPs) with significantly higher gene transfection efficiency than that of dendrimers without AuNPs entrapped due to the fact that the entrapment of AuNPs helps preserve the 3dimensional spherical morphology of dendrimers, allowing for more efficient interaction between dendrimers and DNA. ${ }^{39}$ Kong et al. recently reported the use of arginine-glycineaspartic (RGD) peptide-modified Au DENPs for highly efficient and specific gene delivery to stem cells. ${ }^{40}$ The native and the RGD-modified PEGylated dendrimers as well as the Au DENPs were used as vectors to transfect human mesenchymal stem cells with plasmid DNA (pDNA) possessing the enhanced GFP and the luciferase reporter genes, as well as pDNA encoding the human bone morphogenetic protein-2 (hBMP-2) gene. Xiao et al. reported Au DENPs modified with folic acid (FA) as a non-viral vectors for targeted gene delivery applications. ${ }^{41}$ Amine-terminated PAMAM dendrimers modified with FA via covalent conjugation were used as templates to synthesize gold nanoparticles. The delivery of pDNA into HeLa cells which has an overexpression of high-affinity FA receptors was used to illustrate the targeting ability of the vectors. Au DENPs-FA vector enables much higher luciferase and EGFP gene expression in HeLa cells overexpressing FAR than the Au DENPs without FA, demonstrating the role played by FA-mediated targeting for enhanced gene transfection in target cells. An interesting study by Xu et al. studied the gene transfection of 
polycation-functionalized Au NPs with five different morphologies (nanospheres, nanooctahedra, arrow-headed nanorods, nanorods with different aspect ratios). ${ }^{42}$ The morphology of $\mathrm{Au}$ NPs is demonstrated to play an important role in gene transfection. The most efficient gene carriers are those fabricated with arrow-headed nanorods whereas nanospheres exhibited the poorest performance in gene transfection. The authors also found that nanorods with lower aspect ratios perform better than higher ones. Cationic polypeptide-gold nanoconjugates can also be synthesized by an environmentally benign one-pot synthesis approach, where polypeptides function as capping agents and as reductants for the formation of gold nanoparticles without the need of an additional reducing agent. ${ }^{43}$ The resulting positively charged polypeptide-conjugated gold nanoparticles are applied for gene delivery showing a gradual and prolonged intracellular uptake and transfection. Sustained transfection is maintained for almost two weeks with no obvious cytotoxicity.

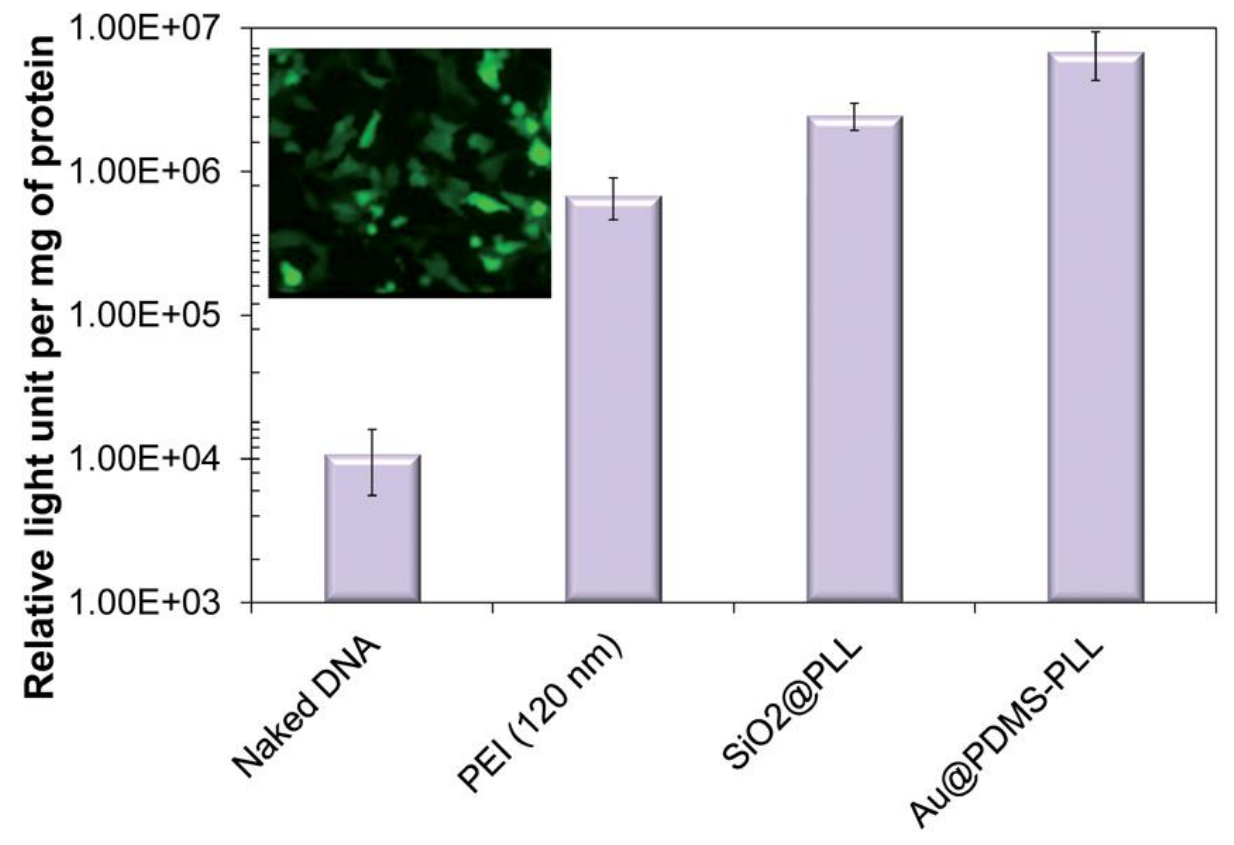

Figure 3. In vitro measurements of gene transfection efficiency of Au@PDMS-PLL nanocomposites including naked DNA, PEI, and SiO2@PLL reference samples. A fluorescence microscopy image of Au@PDMS-PLL-EGFP complexes is also displayed.

\section{Magnetic nanoparticles}


The use of magnetic materials have been tried and tested in commercial biological applications such as diagnostics and biosensors. ${ }^{44-50}$ The crucial mediation and precise control of the interface between the inorganic phase of the material and the organic phase of the material are important considerations to success. Biomolecular recognition as well as biocompatibility can be tailored by modulating the organic phase, while physical properties such as magnetism can be elicited from the inorganic phase. Magnetic spherical particles which have dimensions extending down to the nanometer scale of $100 \mathrm{~nm}$ or less have been used for medical applications. Commercial magnetic nanoparticles (MNPs) are commercially available and have been exploited as gene delivery nanocarriers. Their small size allows MNPs to penetrate into cells. Ferrofluids made from magnetic ferrite nanoparticles are an important class of magnetic nanomaterial. Ferrofluids are extensively utilised in many applications such as audio speakers, smart seal magnetic circuits, and magnetic domain detectors. MNPs have also been suggested for different applications such as high-density magnetic data storage, ${ }^{51,} 52$ magnetic resonance imaging, ${ }^{53-55}$ catalyst supports, ${ }^{56}$ and biomedical applications such as magnetic carriers for bio-separation ${ }^{57,58}$ and enzyme and protein immobilization ${ }^{59}$ and contrast-enhancing media. ${ }^{60}$ In addition, nanoparticles have been coated with a shell of stable and biocompatible material such as silica $\left(\mathrm{SiO}_{2}\right)$ to avoid potential toxic effects on cells. ${ }^{61,62}$

One of the uses of magnetic nanoparticles is in cell imaging. In recent examples, transmission electron microscopy (TEM) or magnetic resonance imaging (MRI) has been used to observe magnetic nanoparticles incorporated within cells. However, TEM and MRI are not convenient for in situ monitoring. Hence, a sensitive and easy technique for monitoring the nanoparticles in cells in situ is desirable. Confocal laser scanning microscopy (CLSM) is a highly sensitive detection technique specific to the fluorescence wavelength of the dye used. 
Lee et al. described a well-controlled, versatile magnetic particle system which can be quantitatively analyzed and provides numerous advantages for commercial applications. In one embodiment, a magnetic motor effect was developed wherein magnetic particles entrapped inside of cells can be used to move the cells in a magnetic field. Gene delivery and specific targeting were also described and experimentally demonstrated. ${ }^{63}$ In another patent, Bikram reported the fabrication of magnetic biomimetic contrast agents which are dual functional: effective for therapeutic gene delivery and magnetic detection. These nanoparticles are made of functionalized iron oxide nanoparticle cores. The shell can be made of an inert gold layer, a layer of inert metal seeds or a silica layer. On top of that, the outermost corona is typically made of up of an outer gold-silver nanoshell and/or a targeting ligand attached to the inert metallic nanoshell. These materials can be used for in vivo magnetic resonance imaging, treating primary or metastatic cancers or ablating atherosclerotic plaque utilising the contrast agents and magnetic particles. ${ }^{64}$ Mykhaylyk et al. have described core-shell magnetic nanoparticles and their self-assembling complexes with viral and non-viral vectors. These nanoparticles were designed and comprehensively characterized based on their morphology, composition and magnetic properties. The protocols, developed with novel magnetic vectors, improve significantly nucleic acid delivery with adeno- and lentivirus vectors and are efficient to transfect primary cells, which are difficult to be transfected. ${ }^{65}$ In another method, a non-viral nanoparticle gene carrier was developed for siRNA delivery and transfection. The gene delivery vehicle was constructed with a core of iron oxide nanoparticles (IOs) and a shell of alkylated polyethyleneimine of $2000 \mathrm{kDa}$ molecular weight. The knockdown efficiency of the siRNA-loaded nanocarriers was assessed with 4T1 cells stably expressing luciferase (fluc-4T1) and further, with a fluc4T1 xenograft model. Significant down-regulation of luciferase was observed, and unlike high-molecular-weight analogues, the coated particles demonstrated good biocompatibility. ${ }^{66}$ 
Magnetic nanoparticles can be used to enhance gene transfection of viral vectors and nonviral vectors. In such systems, the genetic material is attached to magnetic nanoparticles and the delivery to the targeted cells are accomplished through the use of high-field/high-gradient magnets. The transfection efficiency of this technique is comparable to commercially available gene transfection agents such as Lipofectamine. The improvement of the overall transfection levels was achieved by using an oscillating magnet array system with results showing an enhancement of the in vitro transfection levels in human airway epithelial cells compared to static field techniques and Lipofectamine tested. ${ }^{67}$ Fouriki et al. investigated the effects of a novel nonviral oscillating magnet array system in enhancing transfection efficiency of primary human mesenchymal stem cells (hMSCs). ${ }^{68}$ Plasmids encoding for GFP were coupled to magnetic nanoparticles (MNPs) and introduced to hMSCs in culture. Magnetic fields generated by magnets positioned below the culture plates direct the MNP/DNA complexes to the cells. The oscillation of the magnetic arrays promoted more efficient endocytosis via mechanical stimulation. This improved transfection efficiency as well as cell viability, additionally; the expression of hMSC-specific cell surface markers was unaffected. This technique was also useful for enhancing the transfection of plasmids to NIH3T3 mouse embryonic fibroblasts, MG-63 osteoblasts and adult cardiomyocytes. ${ }^{69-71}$

\section{Carbon nanotubes (CNTs)}

CNTs have been widely explored for potential biomedical applications since the first publication of CNT in $1991 .^{72-76} \mathrm{CNTs}$ are one dimensional tubes of rolled-up graphene layers, with a length ranging from hundreds of nanometers up to tens of microns. Singlewalled carbon nanotubes (SWNTs) are composed of a single graphene sheet with a diameter as small as $0.4 \mathrm{~nm}$. Multi-walled carbon nanotubes (MWNTs) are made up of multiple concentric SWNTs with a diameter of about $100 \mathrm{~nm}$. Biomolecules, imaging agents and drugs can be routinely tethered onto the surface of the CNTs via well documented 
functionalization procedures. Functionalization of CNT surface can be typically done by (1) oxidation of the CNTs in acidic conditions and 1,3-dipolar cycloaddition reaction, yielding a covalently linked functionality or (2) hydrophobic or $\pi-\pi$ stacking between the CNTs and another non-polar ring such as the backbone of DNA to produce non-covalent conjugates. The resultant water-soluble CNT constructs can subsequently be used for gene delivery purposes. Essentially ammonium-functionalized CNTs can bind plasmid DNA by electrostatic attractions. The entire bioconjugate can then penetrate the cell membrane through a nano-needle model as visualized by TEM (Figure 2). ${ }^{77}$ Notably, CNTs are considered as exceptional nanomaterials for gene and drug delivery, as they offer an uptake pathway independent of endocytosis of mammalian cells. Both SWNTs and MWNTs have also been found to form stable complexes with plasmid DNA and allow for the successful delivery of genes. ${ }^{78,79}$ Moreover, fluorescent markers and biomolecules have been attached to the CNT walls for studying the cellular uptake efficiency. In particular, CNTs were covalently linked with fluorescein or biotin to form a fluorescent biotin-avidin complex in a study on in vitro uptake. ${ }^{80}$

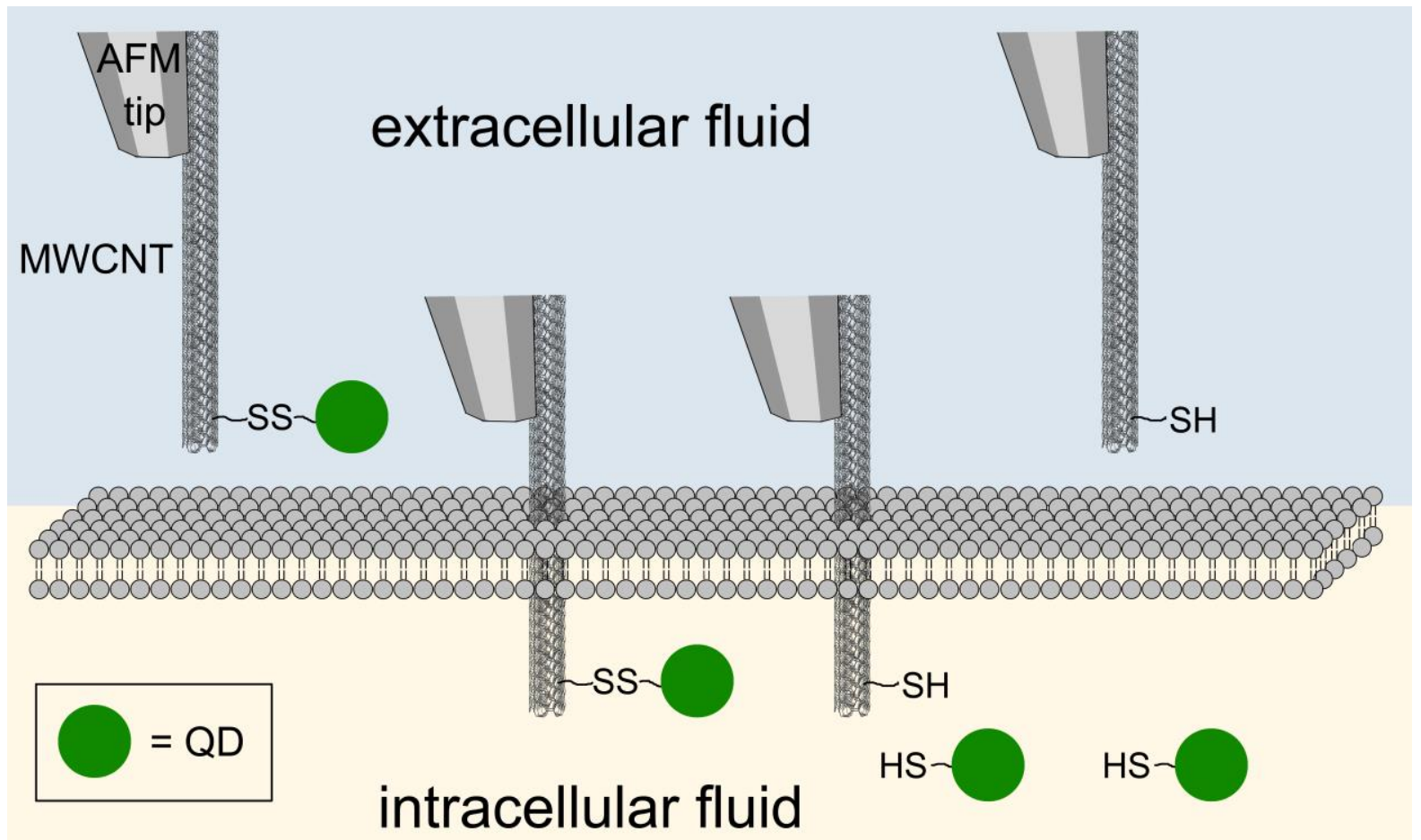


Figure 2. Direct injection and release of quantum dots (QD, green spheres) as mediated by a multi-walled carbon nanotube (MWNT) attached on an AFM tip.

\section{Graphene}

Graphene/CNT composites were used for gene transfection of pIRES plasmid conjugated with green fluorescent protein (GFP) in NIH-3T3 and NG97 cell lines. ${ }^{81}$ Oxygen groups were attached on the MWCNT surfaces by plasma treatment. The composites and pIRES plasmid conjugated with the GFP gene were physically mixed and used for gene transfection with low cytotoxicity and good transfection efficiency. Surface-initiated ATRP of (2-dimethyl amino)ethyl methacrylate (DMAEMA) was used to tailor the GO surfaces in a wellcontrolled manner, producing a series of organic inorganic hybrids (termed as SS-GPDs) for highly efficient gene delivery. Under reducible conditions, the PDMAEMA side chains can be readily cleavable from the GO backbones, benefiting the resultant gene delivery process. Moreover, due to the conjugated structure of the graphene basal plane, SS-GPD can attach and absorb aromatic, water insoluble drugs, such as 10-hydroxycamptothecin (CPT), producing SS-GPD-CPT. The MU assay and the simultaneous double-staining procedure revealed that SS-GPD-CPT possessed a high potency of killing cancer cells in vitro. Chitosan was covalently conjugated to graphene oxide through an amidation process. ${ }^{82}$ The chitosangrafted GO sheets possess good aqueous solubility and biocompatibility. The chitosangrafted GO sheets could condense plasmid DNA into stable, nanosized complexes, and the polyplexes exhibited reasonable transfection efficiency to cells. In another system, GO was bound with PEI with two different molecular weights $(1.2 \mathrm{kDa}$ and $10 \mathrm{kDa}) .{ }^{83}$ It appears that GO conjugated with PEI-10k complex shows greatly reduced toxicity to the treated cells compared to the pristine polymer. A demonstration of intracellular transfection of the enhanced green fluorescence protein (EGFP) gene in HeLa cells was successful. Interestingly, EGFP transfection with PEI-1.2k was ineffective, but high EGFP expression was observed 
using the corresponding GO-PEI-1.2k as the transfection agent. GO-PEI-10k shows similar EGFP transfection efficiency but possessed lower toxicity compared with PEI-10k. A similar system studied by Kim et al. also showed that the incorporation of GO improved DNA binding and condensation/transfection efficiency. ${ }^{84}$ Additionally, the modified GO was used for sensing and bioimaging as it possessed tunable and inherent electrical and optical properties. The authors also showed high transfection efficiency comparable to that of highmolecular weight BPEI, it was also non-toxic and could be extended to siRNA delivery and potentially photothermal therapy. This was further investigated by the same group in the development of an externally stimuli-triggered spatially and temporally controlled gene delivery system. ${ }^{85}$ A photothermally controlled gene delivery carrier, synthesized by linking a low molecular-weight BPEI and reduced GO (rGO) through a hydrophilic PEG spacer. The hybrid system forms a stable nano-sized complex with plasmid DNA (pDNA) and showed better gene transfection efficiency without significant toxicity compared to unmodified controls in PC-3 and NIH/3T3 cells. NIR irradiation led to accelerated endosomal escape of polyplexes augmented by locally induced heating of the hybrid system leading to an enhancement of the gene transfection. Chen et al. also showed that this GO-PEI system shows excellent condensation of DNA at a low N/P ratio. ${ }^{86}$ The PEI-GO is also greatly less cytotoxic than PEI $25 \mathrm{kDa}$. The transfection efficiency of PEI-GO was also higher than that of the PEI $25 \mathrm{kDa}$ at optimal mass ratio. Graphene functionalized with oleatepolyamidoamine (PAMAM) dendrimers hybrids were examined for its gene transfection efficiency. ${ }^{87}$ The PAMAM dendrimers were densely tethered onto the graphene surface and showed good dispersity and aqueous stability. The hybrid materials did not show significant toxicity to HeLa and MG-63 cells. The delivery of plasmid DNA encoding for GFP was used as an indicator of gene transfection capability of the hybrids. Interestingly, the ultrasonicated graphene shows some gene transfection ability and the surface modification of graphene with 
oleic acid/PAMAM further improves the gene transfection efficiency by 13 times. Patterned GO substrates were fabricated for gene transfection using an imprinting approach by mechanical pressure (Figure 3). ${ }^{88}$ This methodology does not require additional chemical reagents and is straightforward and robust. PEI/pDNA complexes were selectively preconcentrated on GO designs, and can be made to release in a sustainable manner. The patterned GO substrates exhibit excellent biocompatibilities and deliver genes encoding for GFP efficiently in a localized manner showing clear boundaries with groups of cells cultured on adjacent areas of the glass. The toxicity of the graphene has been a subject of intense study as well. This is covered in depth in a recent review. ${ }^{89}$ Graphene appears not to have much toxicity against selected bacteria and a mild cytotoxic action on Caco- 2 cells after $24 \mathrm{~h}$ of exposure. ${ }^{90}$ The theoretical evaluation of the toxicity of graphene can be investigated with large-scale all-atom molecular dynamics simulations. ${ }^{91}$ It appears that the hydrophobic protein-protein interaction critical to biological functions are interrupted by the insertion of a graphene nanosheet, as it is energetically favorable for a graphene nanosheet to enter the hydrophobic interface of two contacting proteins, such as a dimer. It has been hypothesized that the forced separation of two functional proteins can disrupt the cells metabolism thus leading to cells mortality. The size of the graphene particles also appears to have an effect. ${ }^{92}$ The increased toxicity of smaller graphene nanoflakes (30 nm vs $80 \mathrm{~nm}$ ) as measured by electrochemical impedance sensing and optical monitoring of treated cells was observed by Yoon et al. The size effect was further probed in another study. Chong et al. further showed that graphene quantum dots (size $\sim 3-5 \mathrm{~nm}$ ) exhibit very low cytotoxicity which was attributed to its ultra-small size and high oxygen content. ${ }^{93}$ In vivo studies revealed no material accumulation in the main organs of mice as well as fast clearance of graphene quantum dots through the kidney. However, it is critical to note that when mice were injected with graphene quantum dots and GO (size $\sim 10-30 \mu \mathrm{m}$, as comparison) multiple times for in 
vivo toxicity tests, GO appeared toxic causing death in mice due to GO aggregation whereas the quantum dots showed no obvious influence on mice, even under multi-dosing situations.
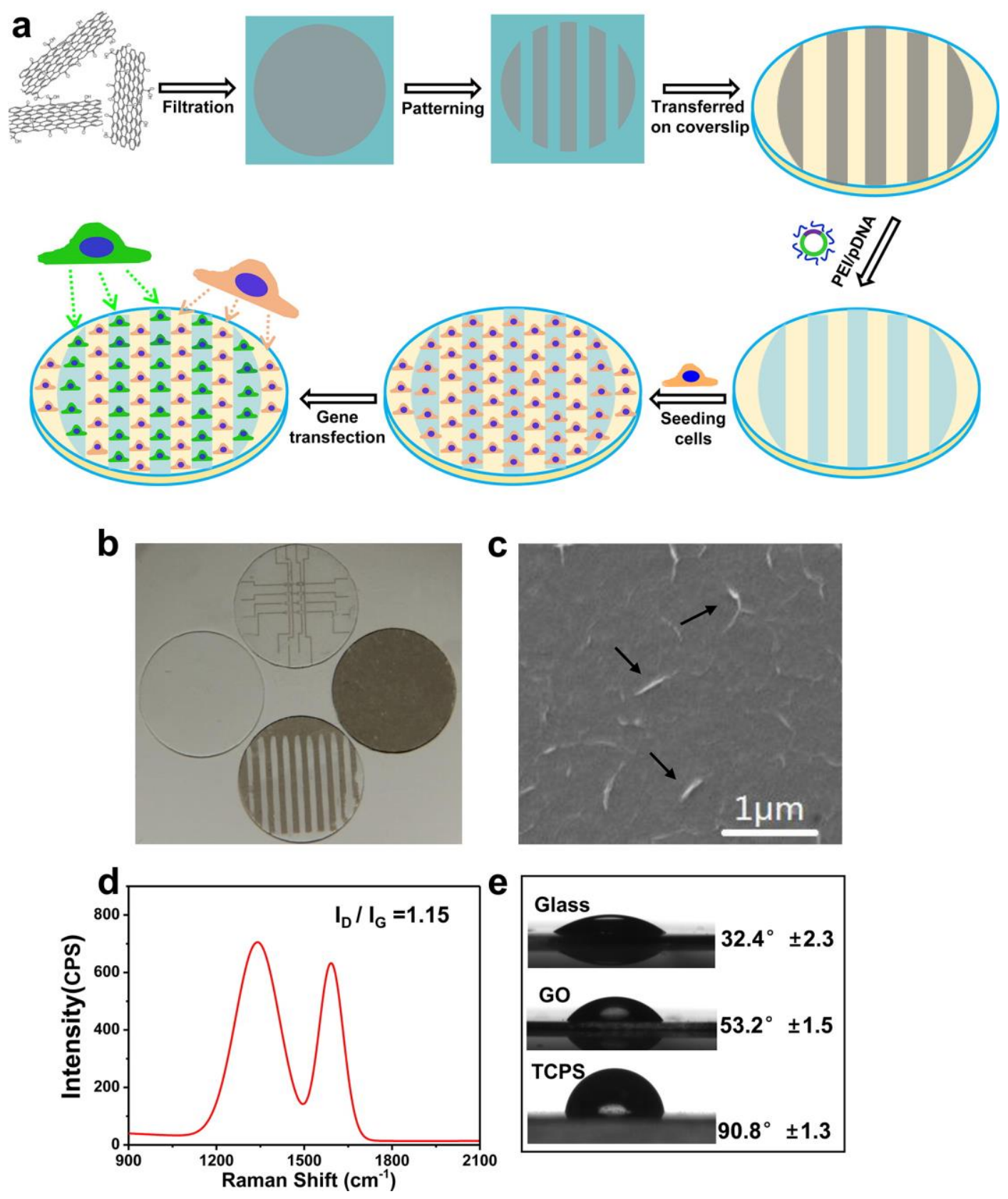

Figure 3. (a) Schematic illustration of preparing patterned GO substrates and the subsequent reverse gene transfection in cells. (b) Optical micrograph showing a panel of patterned GO substrates. (c) SEM image of GO substrates, black arrows indicating the wrinkles on the surface of GO. (d) Raman spectrum of GO substrates. (e) Contact angle of GO substrate, compared with glass and tissue culture plate.

\section{Quantum dots (QDs)}


Utilising QDs as siRNA carriers is one of the efficient methods to achieve this purpose because QDs is luminous and can be used as fluorescence probes for living cells, in vivo cancer targeting and diagnostics. ${ }^{94-98}$ Although the cytotoxicity of QDs limited its biological applications, this problem has been improved by organic-hydride modification. Quantum dot (QDs) can be used as bioimaging agents and delivery vehicles for gene therapeutics in cells. Yang et al. designed multiple QD bundled nanoparticles (NPs) to investigate the effect of QD size and poly(ethylenimine) (PEI) coating on the efficiency of gene delivery into human mesenchymal stem cells (hMSCs). ${ }^{99}$ Gene-complexed QD bundled NPs could be detected in the hMSCs using several different methods such as fluorescence-activated cell sorter, confocal laser scanning microscopy, and in vivo optical imaging. Particularly, the largest QD bundled NPs examined, $20 \mathrm{~nm}$ QDs, had a much higher uptake capability and greater gene expression ability than the other QD NPs $(15 \mathrm{~nm}>10 \mathrm{~nm}>5 \mathrm{~nm})$. Antibacterial fluorescent carbon dots have also been reported for gene transfection applications. ${ }^{100}$ Derfus et al. described the conjugation of siRNA and tumour targeting peptides on the surface of a PEGlyated quantum dot core as a scaffold (Figure 4). The targeting peptide was required for targeted internalization by tumor cells. Utilising an enhanced green fluorescent protein (EGFP) model system, the role of conjugation chemistry was investigated, with siRNA attached to the particle by disulfide cross-linkers showing greater silencing efficiency than when attached by a non-reducible thioether linkage. Delivery of these peptide/siRNA-QDs to EGFP-transfected HeLa cells and release from their endosomal entrapment led to significant knockdown of EGFP signal. The authors suggested designing the siRNA sequence against a therapeutic target (e.g., oncogene) instead of EGFP, and utilising this technology to simultaneously treat and image metastatic cancer. ${ }^{101}$ 


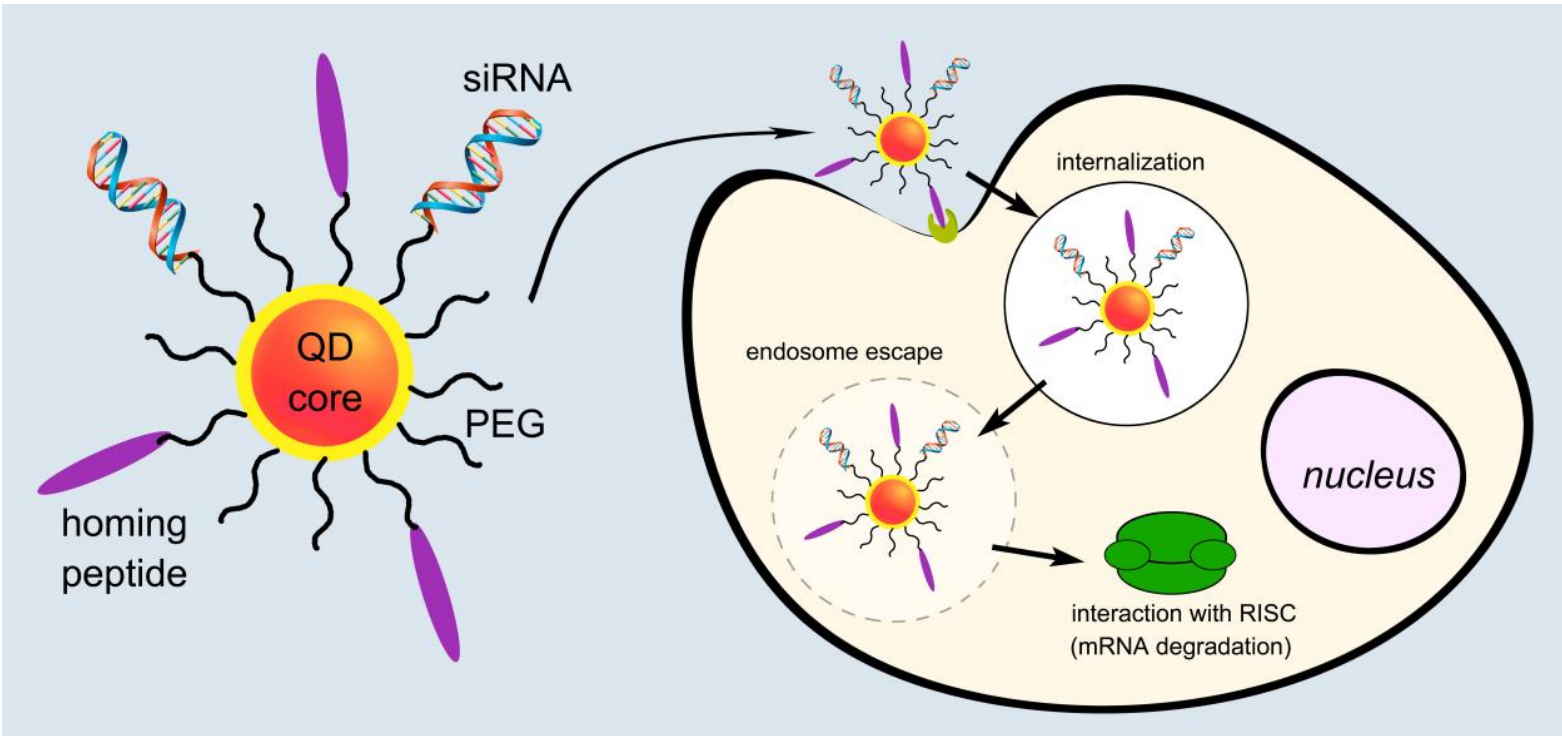

Figure 4. Multifunctional quantum dots for siRNA delivery.

Li et al. demonstrated in his paper that water-soluble and cysteamine protected CdTe QDs, which were positively charged in neutral condition, formed larger complexes with plasmid DNA through simple electrostatic attractions. The transcriptional activity of DNA was inhibited by the formation of the QDs-DNA complexes. When GSH was added at intracellular concentrations, the entrapped DNA was released and recovered the ability to express the reporter protein in HEK 293 cells. The strong association and burst release mediated by GSH at intracellular concentrations without obviously injuring the transcriptional viability of DNA implied that this positively charged QDs had the potential to be used as a new visible vehicle for gene or drug delivery. ${ }^{102} \mathrm{Li}$ et al. demonstrated the design of functional quantum dots to overcome barriers in siRNA delivery such as siRNA protection, cellular penetration, endosomal release, carrier unpacking, intracellular transport and gene silencing. In that paper, two L-arginine-functional-modified CdSe/ZnSe QDs were synthesized as siRNA carriers to silence HPV18 E6 gene in HeLa cells. The QDs coated with $\beta$-CD-1-Arg (where $\mathrm{CD}=$ cyclodextrin) demonstrated optimized property compared with those coated only with 1-Arg. Furthermore, these QDs complexes could also be used as nanocrystal probing agents, allowing real-time tracking and localization of QDs during 
delivery and transfection. The properties and capabilities of these QDs demonstrated that amino acid-modified QDs could be used as useful siRNA carriers to efficiently silence a target gene as well as fluorescence probes to analyze intracellular imaging in vivo. ${ }^{103}$ Zhao et al. reported a new class of multifunctional nanoparticles for siRNA delivery. The carboxyl groups in the $\beta$-CD coupled to amino acid ligands were used as the anchoring groups to replace the organic alkylamine ligands-coated on $\mathrm{CdSe} / \mathrm{ZnSe}$ core-shell nanocrystals, as well as the anchoring groups to link other functional molecules. The $\beta$-CD coupled to amino acids improved the solubility and stability of the coated QDs in cell culture media, kept the long fluorescence lifetime, and reduced cellular toxicity. These nanoparticles were used to examine the cellular uptake and intracellular transport of QDs in living cells. Compared with current siRNA delivery reagents, such as siPort NeoFX, and HiPerFect, the gene-silencing activity of the QDs was slightly improved for HPV18 E6 gene in HeLa cells. In addition, the QDs should also provide a bright and stable fluorescent signal for intracellular siRNA imaging. ${ }^{104}$ Amphiphilic polyethyleneimine derivatives (amPEIs) were synthesized and used for the encapsulation of QDs. ${ }^{105}$ These particles showed very efficient QD cellular labeling with the labeled cell fluorescence intensity more than 10 times higher than conventional techniques such as Lipofectamine-assisted QD delivery. This material could be used for a combination of gene delivery, cell-specific labeling, and ratiometric oxygen sensing. Codelivery of QDs and GFP silencing RNAs was successfully demonstrated by assembling siRNAs to the outer surfaces, which showed the transfection efficiency an order of magnitude higher than conventional gene transfections. Specific gene transfection can be achieved by conjugating hyaluronic acids onto the QD-amPEI for cell-specific targeted labeling showing the specific-to-nonspecific signal ratio over 100. Shao et al. combined an HSV-TK/GCV suicide gene system and near-infrared quantum dots for liver cancer treatment and simultaneous tumor imaging. ${ }^{106}$ A targeting capability was added by developing a folate- 
modified theranostic liposome (FL/QD-TK) comprising an HSV-TK suicide gene covalently coupled to CdSeTe/ZnS core/shell QDs. FL/QD-TK exhibited highly specific tumor imaging and strong inhibition of the folate receptor-overexpressed Bel-7402 mouse xenografts without systematic toxicity. Conjugating ligands with nanoparticle-based carriers for specific delivery of therapeutic nucleic acids (such as antisense oligonucleotides and siRNA) to tumor sites is promising for the treatment of cancers. Inherent weaknesses such as a lack of selectivity and poor transfection efficiency have limited applications. Zhang et al. designed a dual receptortargeted QDs gene carrier QD-(AS-ODN+GE11+c(RGDfK)) with increased cellular uptake efficiency and enhancement in transfection efficiency. ${ }^{107}$ In this case, peptides GE11 and c(RGDfK) which could recognize epidermal growth factor receptors (EGFR) and integrin alpha $v$ beta 3 receptors were conjugated to the nanoparticles, respectively. Synergistic effect between EGFR and integrin $\alpha v \beta 3$ enhanced the cellular uptake of QDs carriers. The effects of inhibition agents showed the endocytosis pathway of QD-(AS-ODN+GE11+c(RGDfK)) probe was mainly clathrin-mediated. This dual receptor-targeted gene carrier achieved desired transfection efficiency.

\section{Upconversion nanoparticles (UCNs)}

Various means have been attempted for gene activation upon delivery. Among them, controlling by light has gained popularity in the past decade. Lanthanide-doped photo-UCNs possess unique optical and chemical properties. UCNs emit high-energy visible light by absorbing several near-infrared (NIR) photons. ${ }^{108}$ The special features allow them to overcome various problems associated UV responsive gene deliveries with similar efficacy but with deeper penetration for gene activation. UCNs have gained enormous attention for photo-controllable gene delivery and have been employed to deliver nucleic acids in gene therapy. In this section, several approaches will be discussed to utilize UCNs based gene delivery vectors for traceable gene delivery and therapy. Zhang's group pioneered the 
research of employing UCNs as gene vectors. In 2009, Zhang's group reported the delivery of siRNA to SK-BR-3 cancer cells with anti-Her2 antibody bonded $\mathrm{NaYF}_{4}$ UCNs. $^{109}$ GL3 siRNA was firstly attached to anti-Her2 antibody and then anti-Her2 antibody conjugated to silica-coated UCNs. The effect of siRNA on gene silencing was confirmed by a luciferase assay. Further work by the group led to the development of another method to monitor the delivery and release of siRNA into live cells via fluorescence resonance energy transfer (FRET) between BOBO-3-stained siRNA and UCNs. ${ }^{110}$ BOBO-3-siRNAs were attached to the surface of amino-group-modified silica/NaYF $4: \mathrm{Yb}, \mathrm{Er}$ UCNs. Subsequently, the intracellular release and biostability of siRNA in live cells was investigated via FRET between UCNs and BOBO3, where UCNs as the donor and the siRNA-intercalating dye BOBO-3 as the acceptor (Figure 5). Once the siRNA was detached from UCNs, the FRET process was inhibited. siRNA release in cells sustained for $24 \mathrm{~h}$, which was observed by confocal microscopy, enabling real-time monitoring of gene release.
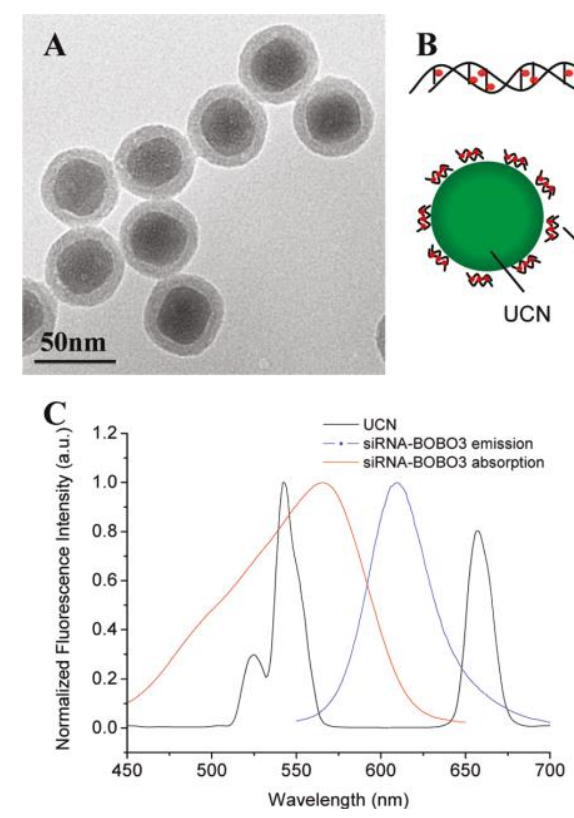

D

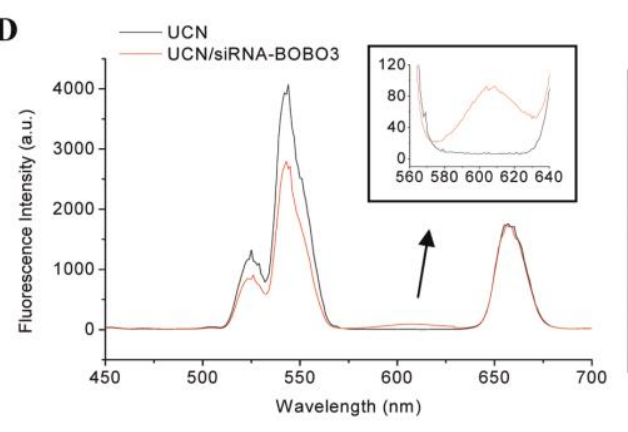

$\mathbf{E}$

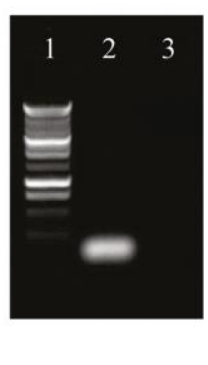


Figure 5. Synthesisof the UCN/siRNA-BOBO3complex. (A)TEM image of silica/NaYF4:Yb,Er upconversion nanoparticles. (B) Schematic drawing of FRET-based UCN/siRNA-BOBO3 complex system. siRNA are stained with BOBO-3 dyes, and the stained siRNA are attached to the surface of NaYF4:Yb,Er nanoparticles. Upon excitation of the nanoparticles at $980 \mathrm{~nm}$, energy is transferred from the donor (UCN) to the acceptor (BOBO-3). (C) Fluorescence spectra of the UCN and siRNA-BOBO3. The spectra are normalized to the same intensity level. (D) Fluorescence spectra of freeUCN solution and UCN/siRNA-BOBO3 complex solution. (E) Gel eletrophoresis image of siRNA. Lane 1, DNA ladder; lane 2, siRNA control; lane 3, free siRNA in the supernatant of UCN/siRNABOBO3 complex. Reproduced from ${ }^{110}$

Similarly, the group continued to report the approach to utilize FRET for gene delivery with

UCNs. ${ }^{111}$ In this approach, POPO-3 dye intercalating the green fluorescent protein (GFP)encoded plasmid DNA was carried by amino-functionalized silica-coated $\beta$-NaYF4:Yb, Er UCNs (Figure 6). FRET between POPO-3 and UCNs was checked with confocal microscopy to track DNA attachment or release. They were able to achieve successful in vitro and in vivo delivery of DNA, which were confirmed by expression of its encoded GFP in Hela cells $24 \mathrm{~h}$ post-transfection and induction of the antibody against the expressed encoded GFP in immunocompetent mice, respectively.

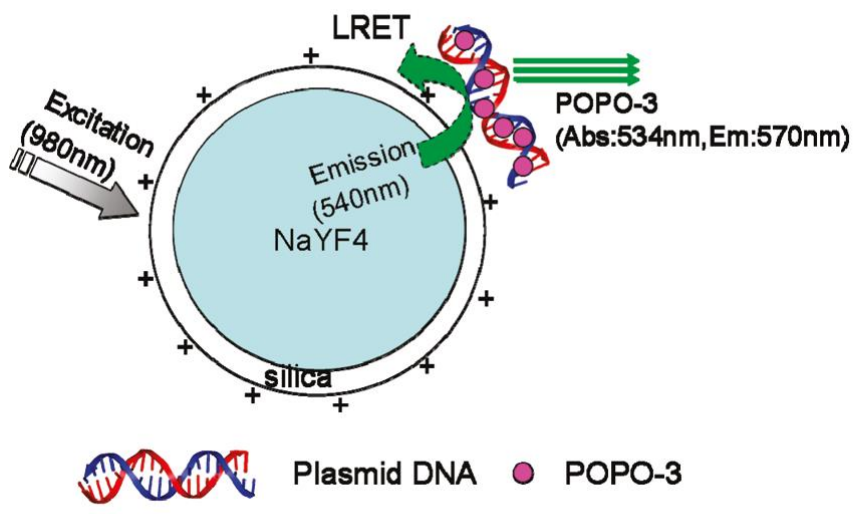

Figure 6. Schematic drawing of LRET occurring between the nanoparticle donor and POPO3 (intercalated into DNA) acceptor. Reproduced from ${ }^{111}$

Recently, Zhang's group reported the use of UCNs (composed with $\mathrm{NaYF}_{4}$ : $\mathrm{Yb}, \mathrm{Tm}$ ) for photoactivation of caged compounds for gene expression in tissue phantoms and mice (Figure 
7). ${ }^{112}$ UCNs acted as nanotransducers to absorb NIR light having high tissue penetration power to emit UV light locally. Plasmid DNA encoding GFP and siRNA targeting GFP mRNA were both caged with 4,5-dimethoxy-2-nitroacetophenone (DMNPE) to block their respective functions. UCNs coated with mesoporous silica were used to carry the caged RNA. Upon NIR light, they were activated by the energy transferred from UCNs, inducing controlled gene expression and subsequently specific gene silencing. Cells transfected with UCNs containing photocaged GFP plasmid were loaded into a polydimethylsiloxane (PDMS) device, which was transplanted into mice. Efficient activation was observed for the cells in the device under NIR light through the skin and PDMS layer.

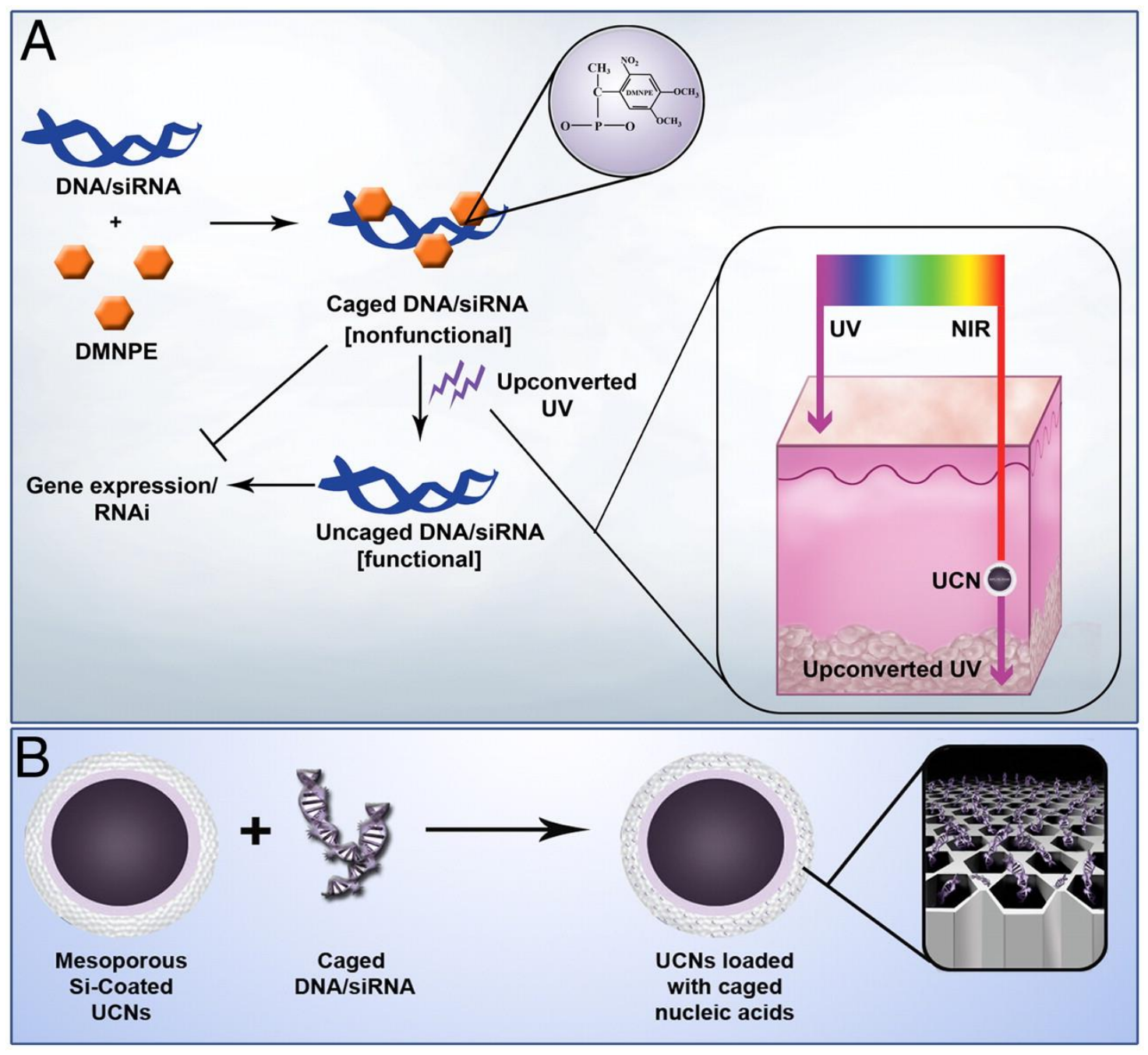


Figure 7. (A) Plasmid DNA and siRNA are caged with DMNPE and then uncaged by upconverted UV light from NIR-to-UV UCNs. Inset shows the penetration depth of UV and NIR light in the skin. (B)Loading of caged plasmid DNA/siRNA into the mesopores of UCNs. Reproduced from ${ }^{112}$.

In a later work, Liu and Xing et. al reported a NIR light-induced siRNA release system with silica coated UCNs (Si-UCNs). ${ }^{113}$ siRNA was loaded to the Si-UCNs carrier by electrostatic force to cationic photocaged linkers covalently linked on Si-UCNs (Figure 8). The system could easily internalized by living cells. Upon NIR light irradiation, the photocaged linker was cleaved off from UCNs by the upconverted UV light, which initiated the intracellular release of the siRNA. The in vitro agarose gel electrophoresis and intracellular imaging results indicated that the Si-UCN-based gene carrier system allowed effective siRNA delivery with UCNs. 

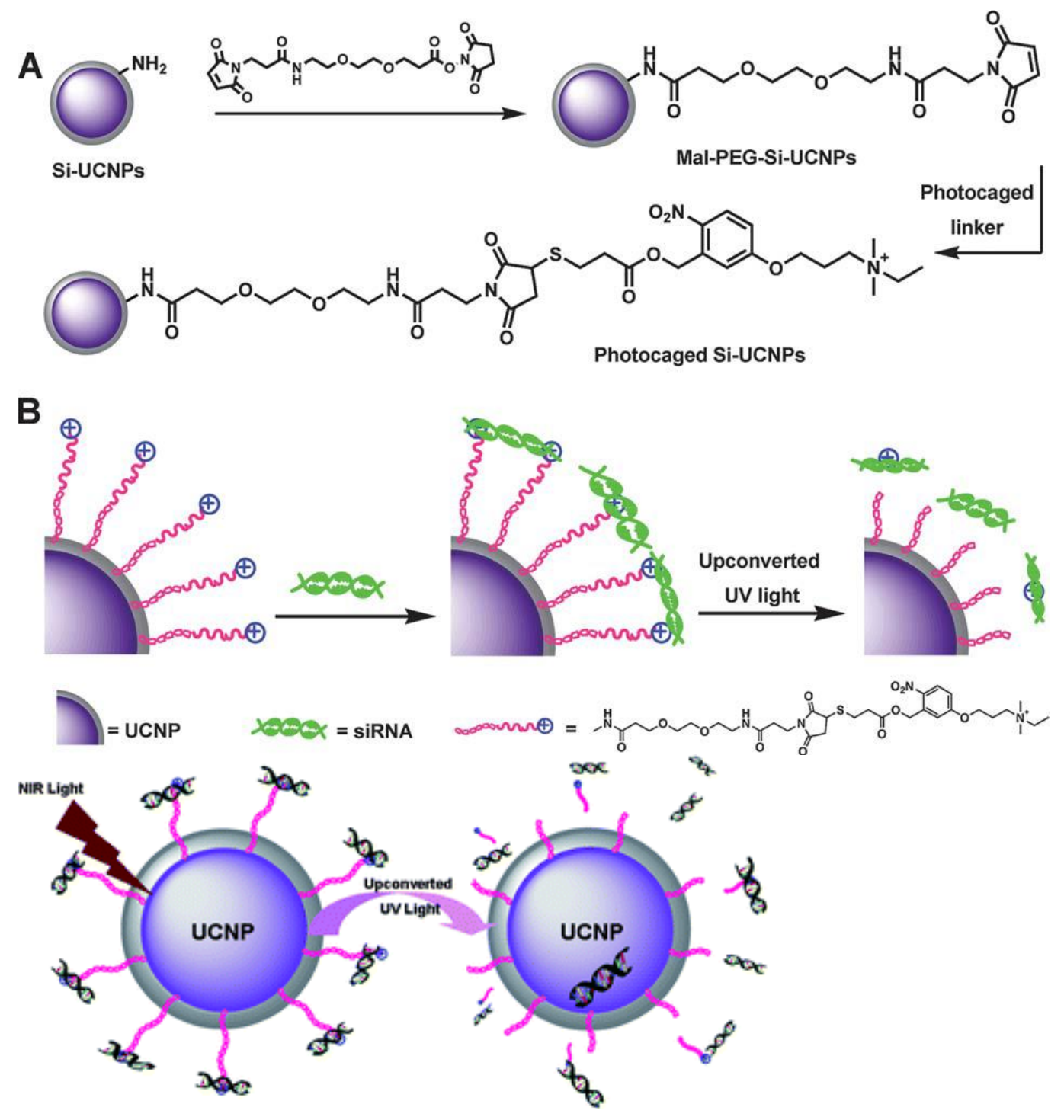

Figure 8. Schematic illustration of (A) the synthesis processes of cationic photocaged SiUCNPs; (B) siRNA adsorption on the particles surface and then photo-release by upconverted UV light from UCNPs. Reproduced from ${ }^{113}$

Li, Guo and Liu reported UCN-PEG@2×PEI complex for delivery of plasmid DNA (pDNA) encoding enhanced green fluorescent protein (Figure 9). ${ }^{114} \mathrm{NaGdF}_{4}$-based UCNs was first modified with poly(ethylene glycol) (PEG) and then with two layers of poly(ethylenimine) (PEI) via covalent conjugation and layer-by- layer assembly, respectively. They found two layer of PEI modification of UCNs showed superior gene transfection efficiency compared to one layer PEI modification in both serum-free media, but slightly less effective than free PEI polymers. In serum-containing media, UCN-PEG@2×PEI showed remarkably enhanced 
transfection efficiency. Gene delivery could be tracked by both upconversion luminescence and magnetic resonance imaging contrasting ability of UCNs.

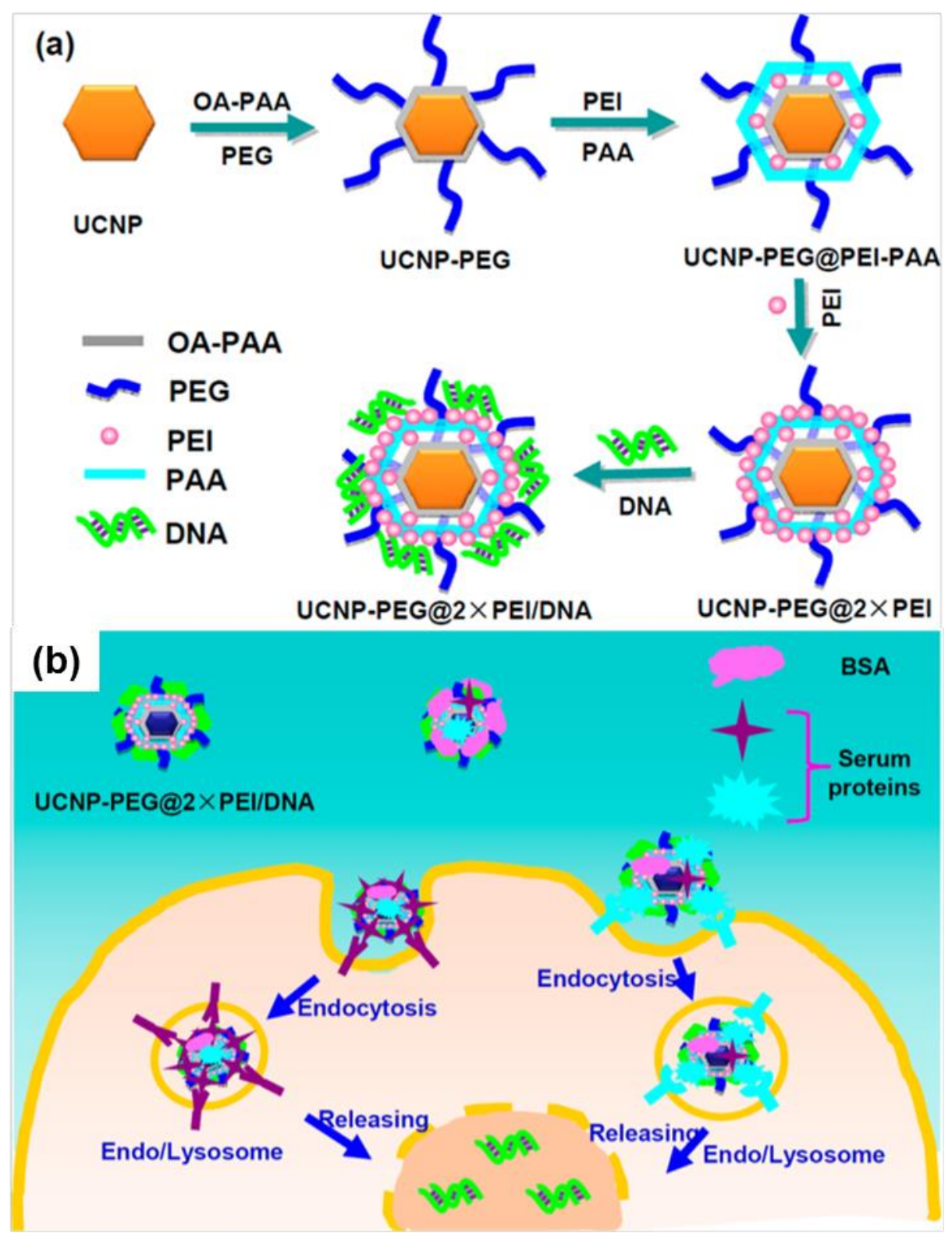

Figure 9. (a) Schematic illustration showing the synthesis of UCN-PEG@2×PEI gene vector and the subsequent pDNA binding. (b) Scheme showing proposed mechanism of serumenhanced gene transfection with our UCN vectors. Reproduced from ${ }^{114}$

Similarly, Lin et al. also reported cationic polymer coated UCNs@PEI for gene transfection (Figure 10). ${ }^{115}$ In vitro studies revealed that transfection efficiency of EGFP plasmid DNA into Hela cells with UCNs@PEI were higher than PEI. Gene silencing was significant as shown by the down regulation of target bcl- 2 mRNA as well. 


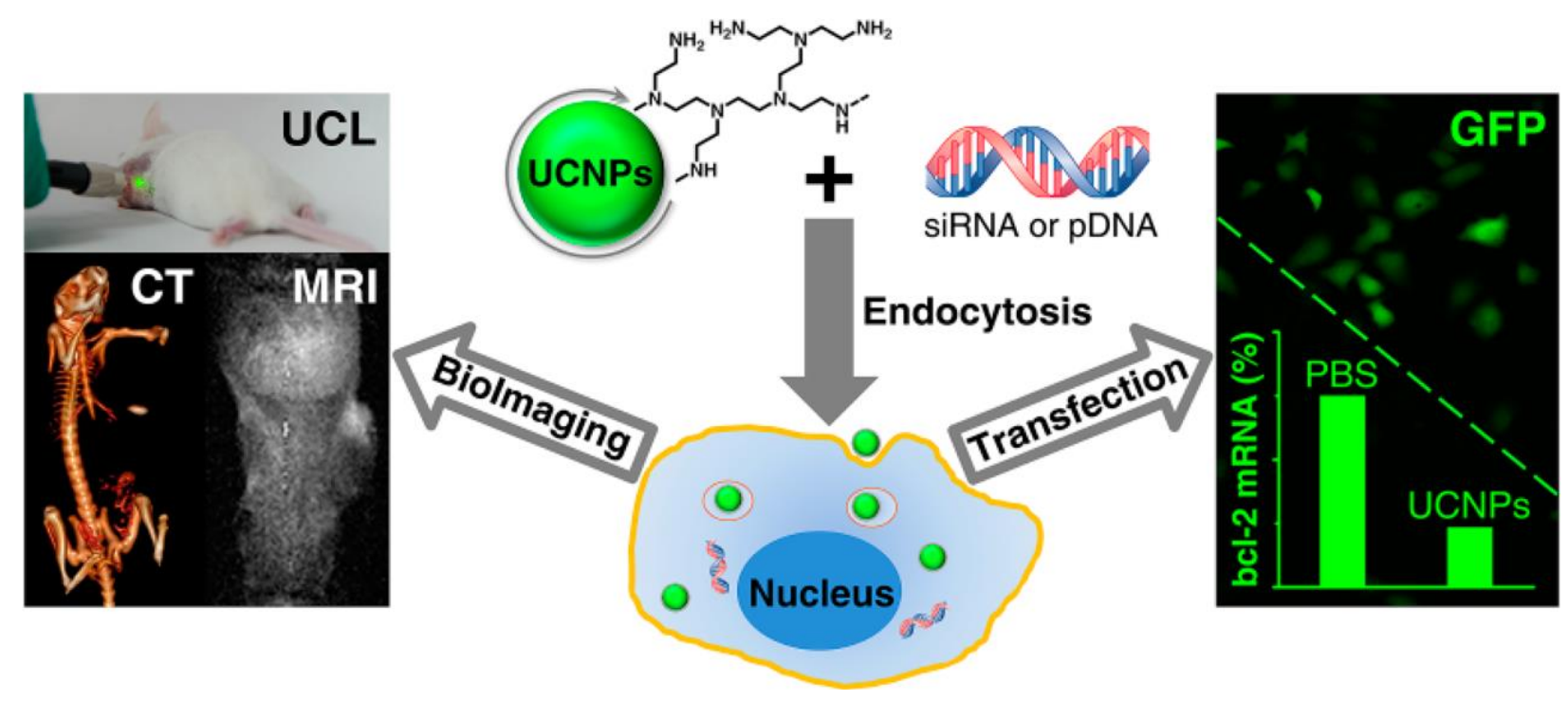

Figure 10. UCNs@PEI for gene delivery and MRI/CT/UCL trimodality imaging.

Very recently, Wang et al. reported polymer coated UCNs for gene delivery. They firstly synthesized positively charged amphiphilic polymer (MFAP) with polysuccinimide (PSI), N(3-aminopropyl) imidazole (NAPI) and oleylamine (OAm). ${ }^{116}$ Then $\mathrm{NaYF}_{4}$ :Yb/Er UCNs were coated with MFAP together with PEG-PLGA, endowing the hydrophilic UCNPs@MFAP nanocapsules with positive charge surface and water dispersibility (Figure 11). Negatively charged pDNA was absorbed on UCNPs@MFAP by electrostatic interaction. GFP encoding pDNA served as an indicator of gene delivery and successful gene transfection by FRET. 


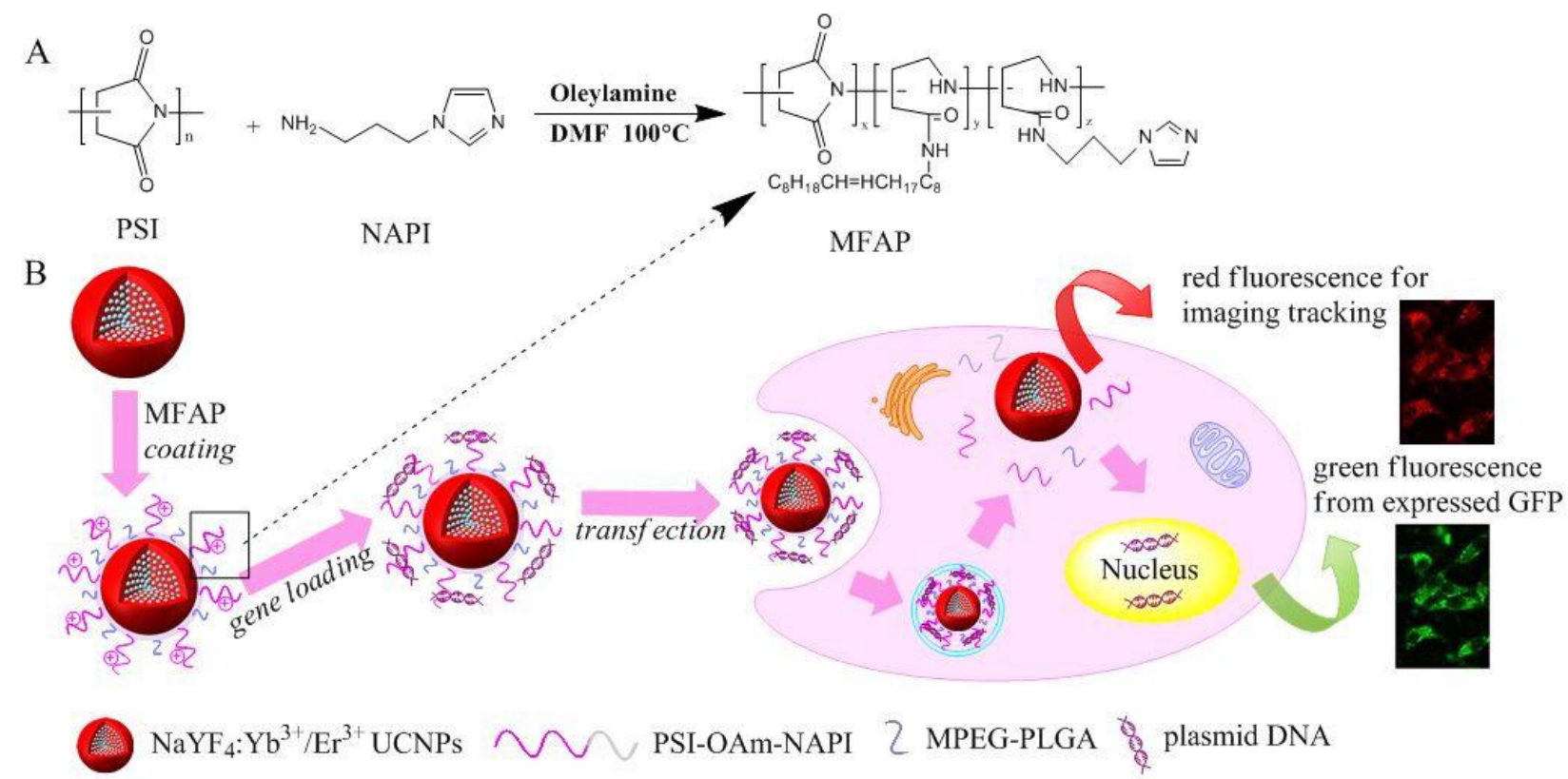

Figure 11. Schematic illustration for the synthesis of amphiphilic polymer (MFAP) (A) and the fabrication of gene nanocapsules, real-time luminescence tracking of gene delivery and monitoring transfection efficiency (B) made it easier to form a uniform and stable composite nanovector. Reproduced from ${ }^{116}$

The above cases showed the possibility of delivering genetic materials with UCNs and to achieve controlled release. To summarize, there are mainly two methods for the UCNs to host the genes as a vector: 1) loading genes in mesoporous silica coated on the UCN surface, 2) Genes are absorbed on positively charged polymer/antibody coated on UCN via electrostatic force. This technique brings the light controlled gene delivery/knockdown to a deeper level in the tissue using safe NIR light, which adds advantages to gene therapy.

\section{Silica nanoparticles}

Mesoporous silica nanoparticle (MSN) is a promising material for biomedical applications, such as delivering drugs or biological molecules (siRNA or DNA) to the target cells or tissues. This is because of focal points, for example, accessibility in permeable structures for encapsulation of medications and genes, extensive surface region to stack biomacromolecules, biocompatibility, material stability, and simple synthesis at cost efficient rates. With positivecharge functionalization on their surface, MSNs are suitable as vectors for siRNA delivery. 
MSNs with small pore size $(\sim 3 \mathrm{~nm})$ have been utilized for plasmid delivery. Xia et al. reported the use of MSNs modified with PEI to adsorb negatively charged plasmid DNA onto the surface for loading and cellular delivery. ${ }^{117}$ Others used cationic materials such as dendrimers ${ }^{118}$ and cationic lipids ${ }^{119}$ for surface modification. Modification of the surface with cationic components was necessary for DNA adsorption. ${ }^{120-122}$ However, the mixing of the genetic material with the MSNs does not fully utilize the mesopores and prevents further modifications on the particle surface. Furthermore, DNAs that are conjugated or adsorbed onto a nanoparticle surface can be easily degraded by nucleases. Therefore, it would be ideal if DNAs are packaged into a protective space for protection against degradation until they are released inside cells. Utilising a strongly dehydrated solution condition, Li et al. have successfully packaged siRNA into the mesopores of magnetic mesoporous silica nanoparticles (M-MSNs). The siRNA-loaded M-MSNs were mixed with PEI to form a polymer layer on their external surface. This method protects the siRNA efficiently and shows negligible cytotoxicity. In gene silencing experiments, these delivery vehicles mediated, with high efficiency, knockdown of both exogenous enhanced green fluorescent protein gene and endogenous B-cell lymphoma 2 (Bcl-2) gene. Kim et al. presented a report on the synthesis of MSNs having very big pores $(>15 \mathrm{~nm})$ and use of the nanoparticles for plasmid DNA delivery to human cells. ${ }^{123}$ The aminated MSNs with big pores allowed a greater loading capacity for plasmids than those with small pores of about $2 \mathrm{~nm}$. The complex of M-MSN with plasmid DNA readily entered into cells without supporting polymers such as cationic dendrimers. Furthermore, M-MSN with big pores could competently protect plasmids from nuclease-mediated hydrolysis and demonstrated higher transfection efficiency of the plasmids encoding luciferase and green fluorescent protein (pLuc, pGFP) compared to M-MSN with small pores $(2 \mathrm{~nm})$. 


\section{Conclusion and Outlook}

At present, the examination of inorganic nanoparticles for good gene delivery is at a developmental stage and one could expect that numerous specialists would be laying cases to their developments. Prior to making a choice on the kind of nanoparticle for good gene delivery applications, a few inquiries must be tended to: What is the quality transfection proficiency? What happens to the nanoparticles after utilization? Are these nanoparticles good for utilization in the body? From these contemplations, research into inorganic nanoparticles for good gene delivery can be visualized to develop in the accompanying areas: i) advancement of novel nanomaterials for good gene delivery; ii) key structure-property relationship examination on cytotoxicity and transfection productivity; iii) lifetime studies; and iv) in vivo practical studies. The examination of vectors for good gene delivery is a wide field of study. It is impossible that any one material will satisfy the necessities of all the diverse applications. Consequently, new materials or mixes of materials must be produced for particular applications. The natural connections between the material and the body are essential variables to consider when utilizing these nanoparticles as a part of the body. For instance, functionalization of the nanoparticle with cell-binding segments could enhance the connection of the molecule to the objective cells, driving the way towards focused on targeted delivery. The steadiness of the nanoparticle ought to be evaluated in sensible profundity. This will permit specialists in this field to have a complete comprehension of the lifetime of the item, the action of different filtering systems in the body and the way of the metabolized and excreted fragments are treated. To date, there are just restricted studies completed to answer these inquiries and more work must be done here. In vivo tests can be completed to examine the flow component and extreme destiny of the nanoparticles in the body and additionally the gene delivery efficiency. This field bears huge useful potential, especially for malignancy medicines and hereditary revision treatment. The combination of 
nanoparticles with soft materials such as hydrogels could potentially drive the area of gene delivery forward. This is able to endow the clinicians seeking gene therapy with new tools such as transfection, imaging, sustained delivery and facile administration in one system. ${ }^{124-}$ 127 The interdisciplinary advancement of these nanoparticles will bring material researchers, scientists, scientific expert and clinicians together in an exploration setting with the regular objective of driving us closer to the day when people will profit by the utilizations of these promising nanocarriers utilized for therapeutic treatment and patient consideration. 


\section{References}

1. M. L. Drumm, H. A. Pope, W. H. Cliff, J. M. Rommens, S. A. Marvin, L. C. Tsui, F. S. Collins, R. A. Frizzell and J. M. Wilson, Cell, 1990, 62, 1227-1233.

2. M. G. Kaplitt, A. Feigin, C. Tang, H. L. Fitzsimons, P. Mattis, P. A. Lawlor, R. J. Bland, D. Young, K. Strybing, D. Eidelberg and M. J. During, Lancet, 2007, 369, 2097-2105.

3. T. J. McFarland, Y. Zhang, B. Appukuttan and J. T. Stout, Expert Opinion on Biological Therapy, 2004, 4, 1053-1058.

4. S. I. Pai, Y. Y. Lin, B. Macaes, A. Meneshian, C. F. Hung and T. C. Wu, Gene Therapy, 2006, 13, 464-477.

5. J. Dobson, Gene Therapy, 2006, 13, 283-287.

6. P. Ghosh, G. Han, M. De, C. K. Kim and V. M. Rotello, Advanced Drug Delivery Reviews, 2008, 60, 1307-1315.

7. J. Li and X. J. Loh, Advanced Drug Delivery Reviews, 2008, 60, 1000-1017.

8. G. Liu, M. Swierczewska, S. Lee and X. Chen, Nano Today, 5, 524-539.

9. S. Jiang, D. Kai, Q. Q. Dou and X. J. Loh, Journal of Materials Chemistry B, 2015, 3, 6897-6904.

10. Z. B. Li and X. J. Loh, Chemical Society Reviews, 2015, 44, 2865-2879.

11. X. J. Loh, Journal of Applied Polymer Science, 2013, 127, 992-1000.

12. X. J. Loh, S. J. Ong, Y. T. Tung and H. T. Choo, Mater. Sci. Eng. C-Mater. Biol. Appl., 2013, 33, 4545-4550.

13. X. J. Loh, S. J. Ong, Y. T. Tung and H. T. Choo, Macromolecular Bioscience, 2013, 13, 10921099.

14. X. J. Loh, S. J. Ong, Y. T. Tung and H. T. Choo, Polymer Chemistry, 2013, 4, 2564-2574.

15. X. J. Loh and Y. L. Wu, Chemical Communications, 2015, 51, 10815-10818.

16. X. J. Loh, Z. X. Zhang, K. Y. Mya, Y. L. Wu, C. B. He and J. Li, Journal of Materials Chemistry, 2010, 20, 10634-10642.

17. H. Y. Ye, C. Owh and X. J. Loh, Rsc Advances, 2015, 5, 48720-48728.

18. M. Thomas and A. M. Klibanov, Appl. Microbiol. Biotechnol., 2003, 62, 27-34.

19. L. Brannon-Peppas and J. O. Blanchette, Advanced Drug Delivery Reviews, 2004, 56, 16491659.

20. I. Brigger, C. Dubernet and P. Couvreur, Advanced Drug Delivery Reviews, 2002, 54, 631-651.

21. D. F. Baban and L. W. Seymour, Advanced Drug Delivery Reviews, 1998, 34, 109-119.

22. J. M. Bergen, H. A. Von Recum, T. T. Goodman, A. P. Massey and S. H. Pun, Macromolecular Bioscience, 2006, 6, 506-516.

23. G. Han, C. C. You, B. J. Kim, R. S. Turingan, N. S. Forbes, C. T. Martin and V. M. Rotello, Angewandte Chemie-International Edition, 2006, 45, 3165-3169.

24. R. Hong, G. Han, J. M. Fernandez, B. J. Kim, N. S. Forbes and V. M. Rotello, Journal of the American Chemical Society, 2006, 128, 1078-1079.

25. M. A. Polizzi, N. A. Stasko and M. H. Schoenfisch, Langmuir, 2007, 23, 4938-4943.

26. E. Y. Ye, M. D. Regulacio, S. Y. Zhang, X. J. Loh and M. Y. Han, Chemical Society Reviews, 2015, 44, 6001-6017.

27. E. Y. Ye and X. J. Loh, Australian Journal of Chemistry, 2013, 66, 997-1007.

28. Y. Lee, S. H. Lee, J. S. Kim, A. Maruyama, X. Chen and T. G. Park, Journal of Controlled Release, 2011, 155, 3-10.

29. V. Cebrian, F. Martin-Saavedra, C. Yaguee, M. Arruebo, J. Santamaria and N. Vilaboa, Acta Biomaterialia, 7, 3645-3655.

30. C. Agbasi-Porter, J. Ryman-Rasmussen, S. Franzen and D. Feldheim, Bioconjugate Chemistry, 2006, 17, 1178-1183.

31. N. L. Rosi, D. A. Giljohann, C. S. Thaxton, A. K. R. Lytton-Jean, M. S. Han and C. A. Mirkin, Science, 2006, 312, 1027-1030. 
32. K. K. Sandhu, C. M. Mclntosh, J. M. Simard, S. W. Smith and V. M. Rotello, Bioconjugate Chemistry, 2002, 13, 3-6.

33. M. Thomas and A. M. Klibanov, Proceedings of the National Academy of Sciences of the United States of America, 2003, 100, 9138-9143.

34. C. Y. Tsai, A. L. Shiau, P. C. Cheng, D. B. Shieh, D. H. Chen, C. H. Chou, C. S. Yeh and C. L. Wu, Nano Letters, 2004, 4, 1209-1212.

35. U.S. Pat., $20110229966,2011$.

36. JP Pat., 2005287507, 2005.

37. WO/2011/016053 2011.

38. J. H. Byeon and Y.-W. Kim, Journal of Materials Chemistry B, 2014, 2, 3185-3189.

39. Y. B. Shan, T. Luo, C. Peng, R. L. Sheng, A. M. Cao, X. Y. Cao, M. W. Shen, R. Guo, H. Tomas and X. Y. Shi, Biomaterials, 2012, 33, 3025-3035.

40. L. D. Kong, C. S. Alves, W. X. Hou, J. R. Qiu, H. Mohwald, H. Tomas and X. Y. Shi, Acs Applied Materials \& Interfaces, 2015, 7, 4833-4843.

41. T. Y. Xiao, W. X. Hou, X. Y. Cao, S. H. Wen, M. W. Shen and X. Y. Shi, Biomater. Sci., 2013, 1, 1172-1180.

42. P. Yan, R. R. Wang, N. N. Zhao, H. Zhao, D. F. Chen and F. J. Xu, Nanoscale, 2015, 7, 52815291.

43. X. H. Yan, J. Blacklock, J. B. Li and H. Mohwald, Acs Nano, 2012, 6, 111-117.

44. US 2005/0130167 2005.

45. US 2003/0092029, 2003.

46. US 2005/0025971, 2005.

47. US 2004/0208825 2004.

48. US 2004/0109824 2004.

49. US 65144812003.

50. US 67676352004.

51. C. Liu, B. S. Zou, A. J. Rondinone and J. Zhang, Journal of the American Chemical Society, 2000, 122, 6263-6267.

52. H. Zeng, J. Li, J. P. Liu, Z. L. Wang and S. H. Sun, Nature, 2002, 420, 395-398.

53. L. Babes, B. Denizot, G. Tanguy, J. J. Le Jeune and P. Jallet, Journal of Colloid and Interface Science, 1999, 212, 474-482.

54. J. M. Perez, L. Josephson, T. O'Loughlin, D. Hogemann and R. Weissleder, Nature Biotechnology, 2002, 20, 816-820.

55. J. M. Perez, T. O'Loughin, F. J. Simeone, R. Weissleder and L. Josephson, Journal of the American Chemical Society, 2002, 124, 2856-2857.

56. T. J. Yoon, W. Lee, Y. S. Oh and J. K. Lee, New Journal of Chemistry, 2003, 27, 227-229.

57. P. S. Doyle, J. Bibette, A. Bancaud and J. L. Viovy, Science, 2002, 295, 2237-2237.

58. H. W. Gu, P. L. Ho, K. W. T. Tsang, L. Wang and B. Xu, Journal of the American Chemical Society, 2003, 125, 15702-15703.

59. D. F. Cao, P. L. He and N. F. Hu, Analyst, 2003, 128, 1268-1274.

60. E. X. Wu, H. Y. Tang, K. K. Wong and J. Wang, Journal of Magnetic Resonance Imaging, 2004, 19, 50-58.

61. M. A. Correa-Duarte, M. Giersig, N. A. Kotov and L. M. Liz-Marzan, Langmuir, 1998, 14, 64306435.

62. Y. Lu, Y. D. Yin, B. T. Mayers and Y. N. Xia, Nano Letters, 2002, 2, 183-186.

63. US 2010/0081130, 2010.

64. US 2010/0003197 2010.

65. O. Mykhaylyk, Y. Sanchez-Antequera, N. Tresilwised, M. Doeblinger, S. Thalhammer, P. S. Holm and C. Plank, Journal of Controlled Release, 148, E63-E64.

66. G. Liu, J. Xie, F. Zhang, Z. Wang, K. Luo, L. Zhu, Q. Quan, G. Niu, S. Lee, H. Ai and X. Chen, Small, 2011, 7, 2742-2749. 
67. S. C. McBain, U. Griesenbach, S. Xenariou, A. Keramane, C. D. Batich, E. Alton and J. Dobson, Nanotechnology, 2008, 19.

68. A. Fouriki and J. Dobson, Nanomedicine, 2014, 9, 989-997.

69. M. Subramanian, J. Lim and J. Dobson, PLoS One, 2013, 8, 8.

70. A. Fouriki, M. A. Clements, N. Farrow and J. Dobson, J. Tissue Eng. Regen. Med., 2014, 8, 169175.

71. A. Fouriki and J. Dobson, Materials, 2013, 6, 255-264.

72. S. lijima, Nature, 1991, 354, 56-58.

73. N. W. S. Kam, Z. Liu and H. J. Dai, Journal of the American Chemical Society, 2005, 127, 12492-12493.

74. Z. Liu, W. Cai, L. He, N. Nakayama, K. Chen, X. Sun, X. Chen and H. Dai, Nature Nanotechnology, 2007, 2, 47-52.

75. Z. Liu, J. T. Robinson, X. Sun and H. Dai, Journal of the American Chemical Society, 2008, 130, 10876-+.

76. Z. Liu, X. Sun, N. Nakayama-Ratchford and H. Dai, Acs Nano, 2007, 1, 50-56.

77. D. Pantarotto, R. Singh, D. McCarthy, M. Erhardt, J. P. Briand, M. Prato, K. Kostarelos and A. Bianco, Angewandte Chemie-International Edition, 2004, 43, 5242-5246.

78. Y. Liu, D. C. Wu, W. D. Zhang, X. Jiang, C. B. He, T. S. Chung, S. H. Goh and K. W. Leong, Angewandte Chemie-International Edition, 2005, 44, 4782-4785.

79. R. Singh, D. Pantarotto, D. McCarthy, O. Chaloin, J. Hoebeke, C. D. Partidos, J. P. Briand, M. Prato, A. Bianco and K. Kostarelos, Journal of the American Chemical Society, 2005, 127, 4388-4396.

80. M. Prato, K. Kostarelos and A. Bianco, Accounts of Chemical Research, 2008, 41, 60-68.

81. L. M. Hollanda, A. O. Lobo, M. Lancellotti, E. Berni, E. J. Corat and H. Zanin, Mater. Sci. Eng. C-Mater. Biol. Appl., 2014, 39, 288-298.

82. H. Q. Bao, Y. Z. Pan, Y. Ping, N. G. Sahoo, T. F. Wu, L. Li, J. Li and L. H. Gan, Small, 2011, 7, 1569-1578.

83. L. Z. Feng, S. A. Zhang and Z. A. Liu, Nanoscale, 2011, 3, 1252-1257.

84. H. Kim, R. Namgung, K. Singha, I. K. Oh and W. J. Kim, Bioconjugate Chemistry, 2011, 22, 2558-2567.

85. H. Kim and W. J. Kim, Small, 2014, 10, 117-126.

86. B. A. Chen, M. Liu, L. M. Zhang, J. Huang, J. L. Yao and Z. J. Zhang, Journal of Materials Chemistry, 2011, 21, 7736-7741.

87. X. Liu, D. Ma, H. Tang, L. Tan, Q. Xie, Y. Zhang, M. Ma and S. Yao, ACS Applied Materials \& Interfaces, 2014, 6, 8173-8183.

88. K. Li, L. Feng, J. Shen, Q. Zhang, Z. Liu, S.-T. Lee and J. Liu, ACS Applied Materials \& Interfaces, 2014, 6, 5900-5907.

89. A. B. Seabra, A. J. Paula, R. de Lima, O. L. Alves and N. Duran, Chemical Research in Toxicology, 2014, 27, 159-168.

90. T. H. D. Nguyen, M. S. Lin and A. Mustapha, Journal of Food Protection, 2015, 78, 996-1002.

91. B. Q. Luan, T. Huynh, L. Zhao and R. H. Zhou, Acs Nano, 2015, 9, 663-669.

92. O. J. Yoon, I. Kim, I. Y. Sohn, T. T. Kieu and N. E. Lee, Journal of Biomedical Materials Research Part A, 2014, 102, 2288-2294.

93. Y. Chong, Y. F. Ma, H. Shen, X. L. Tu, X. Zhou, J. Y. Xu, J. W. Dai, S. J. Fan and Z. J. Zhang, Biomaterials, 2014, 35, 5041-5048.

94. X. H. Gao, Y. Y. Cui, R. M. Levenson, L. W. K. Chung and S. M. Nie, Nature Biotechnology, 2004, 22, 969-976.

95. X. H. Gao, L. L. Yang, J. A. Petros, F. F. Marshal, J. W. Simons and S. M. Nie, Current Opinion in Biotechnology, 2005, 16, 63-72.

96. T. Jamieson, R. Bakhshi, D. Petrova, R. Pocock, M. Imani and A. M. Seifalian, Biomaterials, 2007, 28, 4717-4732. 
97. I. L. Medintz, H. T. Uyeda, E. R. Goldman and H. Mattoussi, Nature Materials, 2005, 4, 435446.

98. X. Michalet, F. F. Pinaud, L. A. Bentolila, J. M. Tsay, S. Doose, J. J. Li, G. Sundaresan, A. M. Wu, S. S. Gambhir and S. Weiss, Science, 2005, 307, 538-544.

99. H. N. Yang, J. S. Park, S. Y. Jeon, W. Park, K. Na and K. H. Park, Biomaterials, 2014, 35, 84398449.

100. Q. Q. Dou, X. T. Fang, S. Jiang, P. L. Chee, T. C. Lee and X. J. Loh, Rsc Advances, 2015, 5, 46817-46822.

101. A. M. Derfus, A. A. Chen, D.-H. Min, E. Ruoslahti and S. N. Bhatia, Bioconjugate Chemistry, 2007, 18, 1391-1396.

102. D. Li, G. Li, W. Guo, P. Li, E. Wang and J. Wang, Biomaterials, 2008, 29, 2776-2782.

103. J.-M. Li, M.-X. Zhao, H. Su, Y.-Y. Wang, C.-P. Tan, L.-N. Ji and Z.-W. Mao, Biomaterials, 32, 7978-7987.

104. M.-X. Zhao, J.-M. Li, L. Du, C.-P. Tan, Q. Xia, Z.-W. Mao and L.-N. Ji, Chemistry-a European Journal, 2011, 17, 5171-5179.

105. J. Park, J. Lee, J. Kwag, Y. Baek, B. Kim, C. J. Yoon, S. Bok, S. H. Cho, K. H. Kim, G. O. Ahn and S. Kim, Acs Nano, 2015, 9, 6511-6521.

106. D. Shao, J. Li, Y. Pan, X. Zhang, X. Zheng, Z. Wang, M. Zhang, H. Zhang and L. Chen, Biomater. Sci., 2015, 3, 833-841.

107. M. Z. Zhang, C. Li, B. Y. Fang, M. H. Yao, Q. Q. Ren, L. Zhang and Y. D. Zhao, Nanotechnology, 2014, 25.

108. Q. Q. Dou, C. P. Teng, E. Y. Ye and X. J. Loh, International Journal of Nanomedicine, 2015, 10, 419-432.

109. J. Shan, Z. Yong, L. Kian Meng, K. W. S. Eugene and Y. Lei, Nanotechnology, 2009, 20, 155101.

110. S. Jiang and Y. Zhang, Langmuir, 2010, 26, 6689-6694.

111. H. Guo, N. M. Idris and Y. Zhang, Langmuir, 2011, 27, 2854-2860.

112. M. K. G. Jayakumar, N. M. Idris and Y. Zhang, Proceedings of the National Academy of Sciences, 2012, 109, 8483-8488.

113. Y. Yang, F. Liu, X. Liu and B. Xing, Nanoscale, 2013, 5, 231-238.

114. L. He, L. Feng, L. Cheng, Y. Liu, Z. Li, R. Peng, Y. Li, L. Guo and Z. Liu, ACS Applied Materials \& Interfaces, 2013, 5, 10381-10388.

115. L. Wang, J. Liu, Y. Dai, Q. Yang, Y. Zhang, P. Yang, Z. Cheng, H. Lian, C. Li, Z. Hou, P. a. Ma and J. Lin, Langmuir, 2014, 30, 13042-13051.

116. X. Bai, S. Xu, J. Liu and L. Wang, Talanta, 2015, DOI: http://dx.doi.org/10.1016/j.talanta.2015.08.038.

117. T. Xia, M. Kovochich, M. Liong, H. Meng, S. Kabehie, S. George, J. I. Zink and A. E. Nel, Acs Nano, 2009, 3, 3273-3286.

118. D. R. Radu, C. Y. Lai, K. Jeftinija, E. W. Rowe, S. Jeftinija and V. S. Y. Lin, Journal of the American Chemical Society, 2004, 126, 13216-13217.

119. J. Liu, A. Stace-Naughton and C. J. Brinker, Chemical Communications, 2009, DOI: 10.1039/b911472f, 5100-5102.

120. F. Kienberger, L. T. Costa, R. Zhu, G. Kada, M. Reithmayer, L. Chtcheglova, C. Rankl, A. B. F. Pacheco, S. Thalhammer, V. Pastushenko, W. M. Heckl, D. Blaas and P. Hinterdorfer, Biomaterials, 2007, 28, 2403-2411.

121. R. J. Lewis, J. H. Huang and R. Pecora, Macromolecules, 1985, 18, 944-948.

122. P. Tam, M. Monck, D. Lee, O. Ludkovski, E. C. Leng, K. Clow, H. Stark, P. Scherrer, R. W. Graham and P. R. Cullis, Gene Therapy, 2000, 7, 1867-1874.

123. M.-H. Kim, H.-K. Na, Y.-K. Kim, S.-R. Ryoo, H. S. Cho, K. E. Lee, H. Jeon, R. Ryoo and D.-H. Min, Acs Nano, 2011, 5, 3568-3576.

124. Q. Q. Dou, S. S. Liow, E. Y. Ye, R. Lakshminarayanan and X. J. Loh, Advanced Healthcare Materials, 2014, 3, 977-988. 
125. X. J. Loh, Materials Horizons, 2014, 1, 185-195.

126. E. Y. Ye, P. L. Chee, A. Prasad, X. T. Fang, C. Owh, V. J. J. Yeo and X. J. Loh, Materials Today, 2014, 17, 194-202.

127. H. Y. Ye, A. A. Karim and X. J. Loh, Mater. Sci. Eng. C-Mater. Biol. Appl., 2014, 45, 609-619. 